\title{
El arrendamiento de vehículos con conductor (VTC) y su entramado jurídico: el avance de Uber, Cabify y la economía colaborativa
}

\author{
Vehicle rental with driver (VTC) and its legal implications. \\ Uber, Cabify and the colaborative economy
}

\author{
Nicolás Alejandro Guillén Navarro \\ Universidad de Zaragoza \\ nicolasg@unizar.es
}

\begin{abstract}
NOTA BIOGRÁFICA
Doctor en derecho por la Universidad de Zaragoza. Máster en práctica jurídica por la Universidad de Zaragoza, Máster en política territorial y urbanística por la Universidad Carlos III de Madrid y Diplomado técnico urbanista por el INAP. Actualmente es director de la Escuela de Turismo Universitaria de Zaragoza, vocal del Consejo de turismo de Aragón y miembro de su Comisión permanente. Sus líneas de investigación se centran en el turismo colaborativo, el turismo sostenible, la accesibilidad y la vivienda protegida.
\end{abstract}

\section{RESUMEN}

En los últimos años, el sector del taxi se enfrenta a la incursión de la economía colaborativa en el transporte urbano de viajeros en automóviles de turismo. Plataformas como Uber o Cabify intentan hacerse un hueco en este sector monopolizado por el taxi, no sin originar un importante conflicto acerca de la legalidad de su actividad. En este sentido, el tránsito de la utilización del modelo de transporte colaborativo al regulado arrendamiento de vehículo con conductor (VTC) ha insertado a este último en la disputa al servir como base legal de actuación de dichas plataformas. Este estudio pretende analizar todas estas cuestiones y cómo se está solventando la pugna entre el sector del taxi y el avance imparable de los VTC, en concreto lo relativo a la problemática regla $1 / 30$ y su tratamiento jurisprudencial.

\section{PALABRAS CLAVE}

Transporte; redes p2p; taxi; VTC; Uber.

\begin{abstract}
In recent years, the taxi industry has faced the incursion of collaborative economy in urban passenger transport in passenger cars. P2P platforms like Uber or Cabify try to compete in this sector monopolized by the taxi. In this sense, the transit of the use of the collaborative transport model to the lease of vehicle with driver (VTC) has legally helped these platforms. However, the debate as to whether the Uber or Cabify benefits should be associated with the principle of freedom to provide services or whether they are included in the transport sector are still present. This study aims to analyze all these issues, focusing both on the legal regime of the taxi, as on the VTC, and how the struggle between the taxi sector and the advancement of these $p 2 p$ service is being solved.
\end{abstract}

\section{KEYWORDS}

Transport; $p 2 p$ service; taxi; VTC; Uber. 


\begin{abstract}
SUMARIO
1. INTRODUCCIÓN. 2. EL ARRENDAMIENTO DE VEHÍCULOS CON CONDUCTOR. 2.1 PROBLEMÁTICA EN CUANTO A LA OBTENCIÓN DE LA AUTORIZACIÓN VTC: EL CRITERIO 1/30. 2.2. ÁMBITO DE ACTIVIDAD, VEHÍCULOS Y SIGNOS DISTINTIVOS. 2.3. DISPOSICIÓN DE VEHÍCULOS, NÚMERO DE CONDUCTORES, TRASMISIÓN DE LICENCIAS Y HOJA DE RUTA. 3. EL SECTOR DEL TAXI FRENTE LA ECONOMÍA COLABORATIVA Y LOS VTC. 4. EL CONFLICTO CON UBER Y CABIFY. 5. CONCLUSIÓN. 6. BIBLIOGRAFÍA.
\end{abstract}

\title{
1. INTRODUCCIÓN
}

El avance de la economía y el consumo colaborativo ha tenido un fuerte impacto en diversos sectores, en especial en el del transporte con la aparición de compañías como Uber, Cabify o Blablacar que, utilizando las redes $p 2 p$, se han hecho un hueco en el entramado del transporte de personas. Esta situación ha generado un importante debate y consecuencias sobre los sectores clásicos del transporte de viajeros que no ven con buenos ojos la entrada de estas compañías y mucho menos su funcionamiento al margen de cualquier marco regulatorio.

No cabe duda de que actualmente existe un enfrentamiento entre las compañías Uber/Cabify y el sector del taxi, con agentes intermedios que se posicionan al lado de unos y otros y en el que en esta batalla el usuario poco o nada puede hacer. Los debates acerca de la situación jurídica de estas plataformas marcan sin duda la problemática con la aparición de pronunciamientos judiciales que paulatinamente van resolviendo un rompecabezas jurídico.

Acciones de competencia desleal, libertad en la prestación de servicios, defensa del usuario, necesidad de autorización o ruptura del monopolio del taxi en favor de una rebaja de los precios son algunos de los elementos que van surgiendo en este tira y afloja de posturas contradictorias que van mutando con el paso del tiempo de conformidad con la evolución a pasos agigantados de las redes $p 2 p$ y de todo aquello que lleva el apelativo «colaborativo».

La disputa por el negocio del transporte público urbano de viajeros en vehículos de turismo ha conllevado el auge de una modalidad hasta ahora relegada a un segundo plano como es el arrendamiento de vehículos con conductor (VTC) como consecuencia de ser la base sobre la que se sostienen actualmente en España plataformas como Uber y Cabify. Vacíos legales, interpretaciones y fallos judiciales se suman a este devenir de ataques al sector de taxi que ve cada vez más amenazada su posición ventajosa adquirida durante décadas. Los cambios en la modalidad de contratación son otro aspecto que hay que tener en cuenta, transitando de la modalidad clásica de contrato directo en la calle o en parada a la preferencia por muchos usuarios de la precontratación a través de soportes informáticos, hechos, ambos dos, que modelan la preferencia por el taxi o el VTC. Asimismo, el tránsito del transporte colaborativo, basado en la conexión de viajeros con simples particulares con vehículo (Uber Pop), a la utilización de vehículos con licencia VTC (Uber X o Cabify), ha desterrado los ataques contra la ilegalidad de la actividad de estas plataformas, la economía sumergida asociada o la competencia desleal ejercida, no sin obviar otras problemáticas paralelas que van surgiendo en este conflicto, las cuales se analizarán a continuación.

\section{EL ARRENDAMIENTO DE VEHÍCULOS CON CONDUCTOR}

El modelo VTC, tan de moda últimamente por su conflicto con el sector del taxi, ha sufrido una interesante evolución en cuanto a su delimitación jurídica. Su vinculación con la figura del taxi es evidente ya que, como se extrae del preámbulo del Reglamento de la Ley de Ordenación de los Transportes Terrestres (Real Decreto 1211/1990, de 28 de septiembre), en adelante ROTT, esta actividad se asocia a la que legalmente venían realizando los vehículos provistos de licencia municipal de la clase C, llamados especiales o de abono ${ }^{1}$. Con ello, es en esta norma donde se extrae su delimitación al

1 Vid. Art. 2 del Reglamento Nacional de los Servicios Urbanos e Interurbanos de Transportes en Automóviles ligeros, aprobado por Real Decreto 763/1979, de 16 de marzo: clase c) «especiales o de abono», vehículos que prestan servicios dentro o fuera de los núcleos urbanizados, diferentes a los de las clases anteriores, ya sea por su mayor potencia, capacidad, lujo, dedicación, finalidad, etc., 
REALA. Nueva Época - N. 9 9, Abril 2018 - ISSN: 1989-8975 - DOI: 10.24965/reala.v0i9.10470 - [Págs. 128-147]

El arrendamiento de vehículos con conductor (VTC) y su entramado jurídico: el avance de Uber, Cabify y la economía colaborativa

Nicolás Alejandro Guillén Navarro

considerarse en su redacción original como actividad de transporte sujeta a autorización administrativa (arts. 180.1 ROTT) $)^{2}$.

Esta delimitación fue alterada posteriormente como consecuencia de los efectos producidos por el art. 21.9 de la Ley 25/2009, de 22 de diciembre, de modificación de diversas leyes para su adaptación a la Ley sobre el libre acceso a las actividades de servicios y su ejercicio, al modificar, entre otros, el art. 134 LOTT e introducir la consideración del arrendamiento de vehículos con conductor como transporte discrecional de viajeros y la sujeción por ende de su ejercicio a todas las reglas contenidas en la Ley ${ }^{3}$. Estos cambios se plasmaron también en el ROTT a través de su modificación por Real Decreto 919/2010, de 16 de julio, introduciendo dicha consideración en el art. 180.1.

La Ley 9/2013, de 4 de julio, de modificación de la LOTT (art. 1.57), suprimió el art. 134 LOTT, además de dar una nueva redacción al artículo 99 LOTT y establecer, en su punto 4, la consideración de dicha actividad como una modalidad más de transporte de viajeros, condicionándose su ejercicio, eso sí, a la obtención de la correspondiente autorización. Además, la Ley 9/2013 añadió otro aspecto más, en concreto en el artículo 48.2, como es una habilitación para que el Estado, por vía reglamentaria, introdujera limitaciones al otorgamiento de nuevas autorizaciones para el ejercicio de esta actividad de transporte.

Estas nuevas modificaciones conllevaron por otra parte la necesidad de adaptar el ROTT, dando con ello nueva redacción a los artículos 181 y 182 a través del Real Decreto 1057/2015, de 20 de noviembre 4 . De estas modificaciones sin duda destaca la conexión de las autorizaciones VTC con las licencias de taxi al establecer el ya famoso límite de 1 licencia VTC por cada 30 de taxi (art. 181.3 in fine), dejando la puerta abierta para que aquellas Comunidades Autónomas que hubieran asumido competencias en materia de autorizaciones de arrendamiento de vehículos con conductor, puedan modificar dicha regla de proporcionalidad siempre que la que apliquen sea menos restrictiva ${ }^{5}$.

En cuanto a la delimitación de la figura del VTC, queda asentado la inexistencia de un precepto centrado en ello, extrayendo la delimitación conceptual del art. 180 ROTT al hablar del simple arrendamiento de vehículos de turismo con conductor. Con ello, esta figura se desmarca por completo del autotaxi. Las diferencias entre los VTC y taxis se centran esencialmente en las autorizaciones requeridas y, sobre todo, requisitos necesarios para su actividad. En este sentido, es importante señalar que, a la hora de hablar de la contratación de este tipo de servicios, existen diferentes modalidades como el servicio contratado en paradas, el servicio contratado directamente en la calle, y el servicio pre-contratado de forma telefónica o mediante otra tecnología de la información y la comunicación. En España, el marco legal existente permite a los taxis operar en las tres opciones, restringiendo su actividad al segmento de la pre-contratación tal y como se extrae del art. 182.1 ROOT ${ }^{6}$. Este hecho, sin duda, recorta la esfera de actividad de los VTC, más cuando los segmentos de parada y contratación directa en la calle son los más

ya porque los conductores tienen conocimientos acreditados superiores a los obligados e inherentes a los de su profesión y apropiados a la especialidad que les caracteriza (turística, representativa, etc.). Vid. TARRÉS VIVES (2012) y CARBONELL PORRAS (2010: pág. 489) y (2017: pág. 1.723-1.724).

2 A esta norma había que asociar diferentes Órdenes de desarrollo centradas en el régimen de autorizaciones. Así, la Orden de 1 de febrero de 1992, daría paso a la Orden de 14 de junio de 1993 de cara a una mayor simplificación del régimen de autorizaciones y ésta, a su vez, a la Orden de 30 de julio de 1998. No obstante, la modificación del ROTT por el Decreto 1225/2006, de 27 de octubre, supuso un reforzamiento de los requisitos exigidos para el acceso al mercado y funcionamiento de las empresas de arrendamiento de vehículos con conductor, dando con ello un nuevo marco jurídico y la aparición de la Orden FOM/36/2008, de 9 de enero, destinada a desarrollar lo dispuesto por el ROTT.

3 Sobre los efectos de la Ley Ómnibus en el arrendamiento de vehículos con conductor: TARRÉS VIVES (2012: pág. 299 y ss.).

${ }^{4}$ En concreto, Real Decreto 1057/2015, de 20 de noviembre, por el que se modifica el Reglamento de la Ley de Ordenación de los Transportes Terrestres, aprobado por Real Decreto 1211/1990, de 28 de septiembre, en materia de arrendamiento de vehículos con conductor, para adaptarlo a la Ley 9/2013, de 4 de julio, por la que se modifica la Ley 16/1987, de 30 de julio, de Ordenación de los Transportes Terrestres y la Ley 21/2003, de 7 de julio, de Seguridad Aérea.

${ }^{5}$ Así, el art. 181.3 ROTT in fine establece: «Se entenderá en todo caso que se produce una situación de desequilibrio, y en consecuencia procederá denegar el otorgamiento de nuevas autorizaciones de arrendamiento de vehículos con conductor, cuando la relación entre el número de las existentes en el territorio de la comunidad autónoma en que pretendan domiciliarse y el de las de transporte público de viajeros en vehículos de turismo domiciliadas en ese mismo territorio sea superior a una de aquéllas por cada treinta de éstas».

${ }^{6}$ Art. 182.1 ROTT in fine: "Los vehículos adscritos a las autorizaciones de arrendamiento de vehículos con conductor no podrán, en ningún caso, circular por las vías públicas en busca de clientes ni propiciar la captación de viajeros que no hubiesen contratado previamente el servicio permaneciendo estacionados a tal efecto. Este conflicto y los efectos competenciales son analizados con profundidad por la Comisión Nacional de los Mercados y la Competencia (2016), en adelante CNMC, y la Organización para la Cooperación y el Desarrollo Económico (2007). 
REALA. Nueva Época - N. 9 9, Abril 2018 - ISSN: 1989-8975 - DOI: 10.24965/reala.v0i9.10470 - [Págs. 128-147]

El arrendamiento de vehículos con conductor (VTC) y su entramado jurídico: el avance de Uber, Cabify y la economía colaborativa

Nicolás Alejandro Guillén Navarro

utilizados en las áreas urbanas densamente pobladas, desplazando la pre-contratación a las periferias urbanas y en las zonas rurales.

Por lo que respecta al régimen del VTC, éste hay que centrarlo en los arts. 181 y 182 ROTT (que derivan a su vez al art. 43.1 LOTT) y la Orden FOM/36/2008, de 9 de enero, de desarrollo de esta actividad. Sobre la autorización, la normativa establece la necesidad de que se obtenga para cada vehículo que se quiera dedicar a esta actividad, la correspondiente autorización administrativa (art.180.2 ROTT). En este sentido, la intervención de las Comunidades Autónomas en este proceso es clave a través de las competencias en cuanto al otorgamiento de autorizaciones de transporte urbano e interurbano, ello sin obviar la competencia estatal para transportes que discurran por más de una CCAA (arts. 149.16 y 1491.21 CE) ${ }^{7}$. De igual manera hay que destacar que salvo Baleares, Canarias, Cataluña o Galicia, las CCAA no cuentan con una regulación exhaustiva del arrendamiento de vehículos con conductor salvo lo referido a la regulación del correspondiente distintivo identificativo o la modificación de la regla de proporcionalidad $1 / 30$, produciéndose una remisión en muchos casos a la regulación estatal ${ }^{8}$.

Centrándonos en los arts. 181 y 182 ROTT, en ellos se recoge el bloque importante de requisitos (número mínimo de vehículos necesarios, características de los mismos, ámbito de actividad, seguros, etc.), salvo los aspectos referidos a la personalidad jurídica del solicitante, nacionalidad o cumplimiento de las obligaciones laborales y sociales que se contienen en la Orden FOM/36/2008, de 9 de enero.

Ante todo, de la regulación del ROTT debe extraerse los límites a la concesión de las autorizaciones VTC, aspecto clave en este tipo de transporte y que articula en gran medida su aparición y consolidación en el sector. Considerado una barrera de protección, el art. 181.3 ROTT incluye la posibilidad de que pueda denegarse el otorgamiento de nuevas autorizaciones de arrendamiento de vehículos con conductor cuando exista una desproporción manifiesta en relación con el transporte público de viajeros en vehículos de turismo, estableciéndose el criterio $1 / 30$.

Sin duda, este hecho marca la problemática de lo referido al VTC, circunstancia no ajena a su análisis jurisprudencial como se verá a continuación, al igual que el conjunto de especificaciones asociadas al otorgamiento de la autorización.

\subsection{Problemática en cuanto a la obtención de la autorización VTC: el criterio 1/30}

Como se ha señalado anteriormente, la regulación del VTC hay que referirla en lo que respecta al régimen de autorizaciones tanto a los arts. 181 y 182 ROTT, como a la Orden FOM/36/2008, de 9 de enero, modificada en 2011 (Orden FOM/3203/2011, de 18 de noviembre) y en 2015 (Orden FOM/2799/2015, 18 noviembre).

Uno de los aspectos más destacados del régimen de autorizaciones es la posibilidad de denegar las preceptivas autorizaciones para la actividad de arrendamiento de vehículos con conductor por razones de proporcionalidad. Esta restricción recogida en el art. 181.3 in fine ROTT, enlazada con el art. 48.2 LOTT, no es algo nuevo debido a que desde las primeras regulaciones sobre el arrendamiento de vehículos con conductor se pueden apreciar ciertas limitaciones en su otorgamiento. Así, el art. 14.2 de la Orden de 30 de julio de 1998, de desarrollo del ROTT, ya recogía la posibilidad de que se pudiera denegar la autorización si existía una desproporción manifiesta entre el número de autorizaciones en el municipio y los potenciales usuarios del servicio. Con ello, y aparte de destacar la acción del Ayuntamiento en el

\footnotetext{
7 Vid. CARBONELL PORRAS (2017), DOMÉNECH PASCUAL (2017) y CANO CAMPOS (2009 y 2010). A este respecto debe tenerse en cuenta el art. 42 LOTT, que supedita la realización de transporte público de viajeros y mercancías a la posesión de «una autorización que habilite para ello, expedida por el órgano competente de la Administración General del Estado o, en su caso, por el de aquella Comunidad Autónoma en que se domicilie dicha autorización, cuando esta facultad le haya sido delegada por el Estado». Este hecho debe conectarse con la Ley Orgánica 5/1987, de 30 de julio, de Delegación de Facultades del Estado en las Comunidades Autónomas en relación con los transportes por carretera y por cable, en concreto el arts. 6 y 8 relativos a transportes discrecionales y arrendamiento de vehículos.

8 Baleares (Decreto 43/2014, de 3 de octubre, que desarrolla y concreta determinados aspectos de la actividad de arrendamiento de vehículos con conductor); Canarias (arts. 79 y ss. de la Ley 13/2007, de 17 de mayo, de transporte por carretera de Canarias); Cataluña (Decreto Ley 5/2017, de 1 de agosto, de medidas urgentes para la ordenación de los servicios de transporte de viajeros en vehículos hasta nueve plazas), Galicia (arts. 45 y ss. Ley 4/2013, de 30 de mayo, del transporte público de personas en vehículos de turismo de Galicia). En el caso de Asturias se identifica directamente una derivación hacia a la regulación estatal en el art. 20.3 de la Ley 1/2014, de 17 de noviembre, de transporte de viajeros por carretera de Cantabria, que dispone: «Para la prestación de servicios de arrendamiento de vehículos con conductor será necesario disponer del correspondiente título habilitante, obtenido en los términos establecidos en la legislación estatal».
} 
REALA. Nueva Época - N. 9 9, Abril 2018 - ISSN: 1989-8975 - DOI: 10.24965/reala.v0i9.10470 - [Págs. 128-147]

El arrendamiento de vehículos con conductor (VTC) y su entramado jurídico: el avance de Uber, Cabify y la economía colaborativa

Nicolás Alejandro Guillén Navarro

proceso de autorización, aparecía una regla de proporcionalidad por la que se extraía su denegación si el número de autorizaciones vigentes domiciliadas en la Comunidad Autónoma rompía la ratio de 1/30 con respecto al de las autorizaciones de transporte discrecional interurbano de viajeros en vehículos de turismo domiciliadas en la misma9 ${ }^{9}$.

Sin duda, a la hora de analizar la problemática que gira en torno a la regla 1/30 hay que hacer mención al art. 14.1 de la Orden FOM/36/2008, de 9 de enero (en su texto original), norma que derogaba a la Orden de 30 de julio de 1998 y que retomaba dicha regla. La habilitación legal sobre la que se sustentaba esta restricción, en concreto los arts. 49 y 50 de la LOTT, desarrollados por los arts. 44 y 45.3 ROTT, no estuvo libre de polémicas sobre todo por los efectos de la Ley 25/2009, de 22 de diciembre, en estos preceptos tal y como ponen de manifiesto diferentes sentencias del Tribunal Supremo ${ }^{10}$.

Con ello, a partir de la entrada en vigor de la Ley 25/2009 se puso en serias dudas el establecimiento del límite 1/30 ante la carencia de una habilitación por parte de una norma con rango de Ley, al entender que tanto el artículo 14.1 de la Orden FOM/36/2008, como el art. 181.2 ROTT, donde también se hacía referencia a la limitación, quedaban fuera de juego desde su entrada en vigor, tal y como apunta el Tribunal Supremo ${ }^{11}$. Ello era debido a la supresión de los arts. 49 y 50 LOTT, que suponían el sustento legal a la regla 1/30, por el art. 21.2 de la Ley 25/2009, no dándose por válido el respaldo de los arts. 3 y 15 LOTT que, por ejemplo, la Resolución de Coordinación 1/10 de la Dirección General de Transporte Terrestre del Ministerio de Fomento defendía.

Toda esta situación provocó un vacío legal hasta que de nuevo la Ley 9/2013, de 4 de julio, a través del artículo 48.2 LOTT, legitimara, con matizaciones, las tan problemáticas limitaciones. A este respecto, conviene apuntar que, aunque esta última Ley, con la reforma operada en la LOTT, dio vía libre a las limitaciones en el otorgamiento de nuevas autorizaciones, el desarrollo reglamentario previsto en su Disposición Final Primera no se produjo hasta el Real Decreto 1057/2015, de 20 de noviembre, y la Orden FOM/2799/2015, 18 noviembre, cerrando con ello la problemática al respecto ${ }^{12}$.

De todas formas, hay que señalar un hecho importante y son las repercusiones jurídicas de la denegación de licencias ya no sólo durante el vacío creado entre 2009 y 2013, sino también en el lapso desde la nueva redacción del artículo 48 LOTT hasta la aprobación del Real Decreto 1057/2015, de 20 de noviembre.

El hecho de la aparición de diferentes sentencias anulando la denegación de autorizaciones ha generado la incorporación de nuevas licencias a través de este respaldo judicial, alimentando con ello el conflicto con el sector del taxi más cuando el Tribunal Supremo tiene que decidir sobre un número indeterminado de solicitudes que oscilan entre las 3.000 de Uber y Cabify según Cruz Peña (2017) o las 10.000 en todo el territorio nacional referenciadas por la Gaceta del taxi (2017).

\footnotetext{
9 La acción de los Ayuntamientos en el proceso de otorgamiento también ha estado presente en las sucesivas reformas del ROTT en concreto en la de 2010 en donde en el art. 181.2, en su apartado 1, se establecía que el Ayuntamiento podía valorar «las circunstancias externas concurrentes a la hora de emitir su informe sobre la procedencia del otorgamiento de las autorizaciones solicitadas, debiendo tenerse en cuenta la distinta naturaleza y el carácter diferenciado del arrendamiento con conductor y de los servicios de transporte en vehículos de turismo».

10 Vid. Por ejemplo, Sentencias del Tribunal Supremo de 27 de enero de 2014 (dos sentencias con esa fecha dictadas en los recursos de casación 5892/2011 y 962/2012), 29 de enero de 2014 (cuatro sentencias con esa fecha dictadas en los recursos de casación 527/2013, 105/2012, 384/2012 y 2169/2012), 30 de enero de 2014 (recursos de casación 110/2012 y 4163/2012), 7 de febrero de 2014 (recursos de casación 2115/2012), 5 de mayo de 2014 (recursos de casación 108/2012, 1438/2012 y 3309/14), 6 de mayo de 2014 (recursos de casación 5896/2011 y 2949/2012), 17 de noviembre de 2014 (recurso de casación 3802/11), 13 de febrero de 2015 (recurso de casación unificación de doctrina 2076/2014) o 25 de enero de 2016 (recurso de casación 134/2014).

11 Vid. las Sentencias del Tribunal Supremo de 27 de enero de 2014 (Recursos de Casación 5892/2011 y 969/2012) y de 29 de enero de 2014 (Recurso de Casación 105/2012). En este sentido, GUIJARRO GONZÁLEZ (2015).

12 El tardío desarrollo reglamentario ha sido fuente también de polémica al apuntarse un nuevo vacío tal y como señalan las sentencias del Tribunal Supremo 1711/2017 y 1713/2017, de 13 de noviembre (recursos de casación núm. $3542 / 2015$ y $3100 / 2015$, respectivamente), las cuales serán analizadas en este estudio. Sus planteamientos se han reflejado en posterior jurisprudencia, en concreto en las STS de 14 de noviembre de 2017 (r. casación núm. 3923/2015), 4 de diciembre de 2017 (r. casación núm. 2180/2015), 18 de diciembre de 2017 (dos sentencias con esa fecha dictadas en los recursos de casación 170/20116 y 885/2016); de 12 enero de 2018 (r. casación núm. 61/2016); 24 enero de 2018 (r. casación núm. 276/2016); 25 enero de 2018 (r. casación núm. 117/2017); sentencias de 29 de enero de 2018; de 30 enero de 2018 (r. casación núm. 3353/2015); 30 enero de 2018 (r. casación núm. 3723/2015), de 2 febrero de 2018 (r. casación núm. 2188/2015); 5 febrero de 2018 (r. casación núm. 281/2017); o 21 marzo de 2018 (r. casación núm. 3835/2015). Por otra parte, se está a la espera de que el Tribunal Supremo resuelva sobre la impugnación por la CNMC del Real Decreto 1057/2015, de 20 de noviembre (vid. Auto del TS de 8 de mayo de 2017).
} 
REALA. Nueva Época - N. 9, Abril 2018 - ISSN: 1989-8975 - DOI: 10.24965/reala.v0i9.10470 - [Págs. 128-147]

El arrendamiento de vehículos con conductor (VTC) y su entramado jurídico: el avance de Uber, Cabify y la economía colaborativa

Nicolás Alejandro Guillén Navarro

A este respecto, los numerosos autos del Tribunal Supremo acerca de la problemática sobre las restricciones y limitaciones aplicables tras la entrada en vigor de la Ley 9/2013 (vid, entre otros, los Autos de 25 de septiembre, 2, 17, 18 y 23 de octubre de 2017) anteceden un terremoto judicial. Así, de nuevo salen a la luz temas como la determinación de «la normativa aplicable a las autorizaciones de alquiler de vehículos con conductor cuyas solicitudes se efectuaron con anterioridad a la entrada en vigor de la Ley 9/2013, pero que fueron resueltas con posterioridad a su entrada en vigor» o "las restricciones y/o limitaciones aplicables para autorizar la actividad de arrendamiento de vehículos con conductor tras la entrada en vigor de la Ley 9/2013 y antes de la aprobación del Reglamento del año 2015» (Auto de 23 de octubre de 2017).

El primer temblor judicial se produjo mediante dos Sentencias de 13 de noviembre de 2017 (Sentencias 1711/2017 y 1713/2017) de la Sala tercera de lo Contencioso-administrativo del Tribunal Supremo por las que se estiman los recursos de Jojucar S. L. y de Gran Vía Rent a Car, S. L., concediéndose respectivamente 60 licencias VTC, a la primera, y 20, a la segunda. En estas sentencias se incorpora la resolución, además de los problemas anteriormente apuntados, de la situación de las solicitudes presentadas después de la entrada en vigor la Ley 9/2013, diferenciando los casos de solicitudes que se hubieran presentado antes o después del desarrollo reglamentario dado por el Real Decreto 1057/2015, de 21 de noviembre.

De nuevo en estas sentencias se resucita la duda acerca de la efectividad del artículo 48.2 LOTT, redactado por Ley 9/2013, de 4 de julio, hasta que se produjo su desarrollo reglamentario. A este respecto, el Tribunal Supremo es claro en señalar que «no cabe aceptar que los artículos 181.2 ROTT y 14.1 de la Orden FOM/36/2008, de 9 de enero, hayan renacido y vuelvan a ser de aplicación a raíz de la nueva redacción dada al artículo 48.2 LOTT, redactado por Ley 9/2013, de 4 de julio». Además estos pronunciamientos dilucidan qué ocurre con las solicitudes de autorización presentadas cuando ya había entrado en vigor la nueva redacción del artículo 48 LOTT dada por Ley 9/2013, de 4 de julio, y antes de que se produjera su desarrollo reglamentario, más cuando las solicitudes del asunto tratado eran de 14 de marzo de 2014 (Sentencia 1713/2017). Así, con base en lo señalado, es clara la tesis que apuesta porque la previsión contenida en el artículo 48.2 LOTT, redactado por Ley 9/2013, de 4 de julio, necesita, para la efectividad de las limitaciones y restricciones que en él se contemplan, del desarrollo reglamentario dado por Real Decreto 1057/2015, de 21 de noviembre.

A pesar de la visión clara del Tribunal Supremo en cuanto a la problemática del vacío legal creado, por parte del sector del taxi se ha discutido mucho esta interpretación. En este sentido, por ejemplo, la Asociación Élite Taxi Madrid (AETM) defiende que el respaldo del límite recogido en el art. 14.1 de la Orden FOM $36 / 2008$ tras la anulación de los arts. 49 y 50 LOTT, seguía existiendo a través de los arts. 92.1.c y 92.2.a LOTT una vez producida la modificación del art. 181 ROTT en 2010 (Real Decreto 919/2010, de 16 de julio). Así, teniendo en cuenta la consideración del arrendamiento con conductor como transporte discrecional de viajeros, la referencia en el art. 92.1.c LOTT a la limitación en el número y/o condiciones de nuevas autorizaciones a otorgar debe, según su parecer, considerarse como válida para paralizar la problemática sobre el vacío legal producido.

Válidos o no los planteamientos del sector del taxi, lo que es evidente es el asentamiento de las interpretaciones del Tribunal Supremo, originándose un goteo continuo de resoluciones que dan lugar al reconocimiento de nuevas licencias rompiendo por completo el panorama equitativo del $1 / 30^{13}$. Resultará interesante realizar un estudio comparativo de los resultados judiciales en la evolución de las autorizaciones VTC en los próximos años. De todos modos, atendiendo a los datos ofrecidos por el Ministerio de Fomento (2017), en septiembre de 2017, preludio a la avalancha de pronunciamientos del Tribunal Supremo, se identificaban un total de 54.267 autorizaciones de taxi frente a las 5.855 autorizaciones VTC (tabla 1). Aplicando la correspondiente regla de proporción, en realidad en España debería haber 1.809 licencias, lo que da idea ya del gran número que se han obtenido por vía judicial. Por otra parte, hay que indicar que en realidad deben sumarse todavía más autorizaciones de carácter autonómico que alcanzan para los taxis un número de 316 frente a los 247 VTC, estando concentradas en Cádiz (48 VTC autonómico), Las Palmas (300 y 319) y Santa Cruz de Tenerife (16 y 80 ).

13 Vid. Sentencia del Tribunal Supremo núm. 1897/2017, de 4 diciembre, que de nuevo señala que la Ley 9/2013, no revitaliza lo dispuesto en el ROTT, sino que es necesario al nuevo desarrollo reglamentario. Así, se señala que «no cabe aceptar que los artículos 181.2 del Reglamento de la Ley de Ordenación de los Transportes Terrestres aprobados por Real Decreto 1211/1990 y 14.1 de la Orden FOM/36/2008, de 9 de enero, hayan renacido y vuelvan a ser de aplicación a raíz de la nueva redacción dada el artículo 48.2 LOTT, redactado por Ley 9/2013, de 4 de julio». 
REALA. Nueva Época - N. 9, Abril 2018 - ISSN: 1989-8975 - DOI: 10.24965/reala.v0i9.10470 - [Págs. 128-147]

El arrendamiento de vehículos con conductor (VTC) y su entramado jurídico: el avance de Uber, Cabify y la economía colaborativa Nicolás Alejandro Guillén Navarro

TABLA 1. DISTRIBUCIÓN AUTORIZACIONES TAXI (NACIONAL) Y VTC (NACIONAL) POR PROVINCIA

\begin{tabular}{|c|c|c|}
\hline PROVINCIA & TAXI & VTC \\
\hline A CORUÑA & 1.481 & 78 \\
\hline ÁLAVA & 236 & 30 \\
\hline ALBACETE & 212 & 5 \\
\hline ALICANTE & 1.271 & 63 \\
\hline ALMERÍA & 494 & 63 \\
\hline ASTURIAS & 1.380 & 106 \\
\hline ÁVILA & 100 & 9 \\
\hline BADAJOZ & 500 & 14 \\
\hline BARCELONA & 10.584 & 780 \\
\hline BIZKAIA & 1.239 & 28 \\
\hline BURGOS & 324 & 43 \\
\hline CÁCERES & 361 & 16 \\
\hline CÁDIZ & 1.081 & 43 \\
\hline CANTABRIA & 505 & 171 \\
\hline CASTELLÓN & 219 & 50 \\
\hline CIUDAD REAL & 261 & 10 \\
\hline CÓRDOBA & 760 & 30 \\
\hline CUENCA & 164 & 10 \\
\hline GIPUZKOA & 657 & 19 \\
\hline GIRONA & 555 & 34 \\
\hline GRANADA & 837 & 55 \\
\hline GUADALAJARA & 112 & 10 \\
\hline HUELVA & 393 & 32 \\
\hline HUESCA & 237 & 6 \\
\hline ISLAS BALEARES & 2.334 & 203 \\
\hline JAÉN & 393 & 3 \\
\hline LA RIOJA & 170 & 6 \\
\hline LAS PALMAS & 3.169 & 30 \\
\hline LEÓN & 517 & 74 \\
\hline LLEIDA & 445 & 0 \\
\hline LUGO & 535 & 13 \\
\hline MADRID & 15.384 & 2.416 \\
\hline MÁLAGA & 2.593 & 502 \\
\hline MURCIA & 752 & 75 \\
\hline
\end{tabular}


REALA. Nueva Época - N. 9, Abril 2018 - ISSN: 1989-8975 - DOI: 10.24965/reala.v0i9.10470 - [Págs. 128-147]

El arrendamiento de vehículos con conductor (VTC) y su entramado jurídico: el avance de Uber, Cabify y la economía colaborativa Nicolás Alejandro Guillén Navarro

\begin{tabular}{lrr}
\hline NAVARRA & 419 & 57 \\
\hline OURENSE & 340 & 20 \\
\hline PALENCIA & 120 & 22 \\
\hline PONTEVEDRA & 1.264 & 38 \\
\hline S. C. TERERIFE & 2.671 & 21 \\
\hline SALAMANCA & 357 & 18 \\
\hline SEGOVIA & 141 & 83 \\
\hline SEVILLA & 2.267 & 153 \\
\hline SORIA & 79 & 0 \\
\hline TARRAGONA & 519 & 46 \\
\hline TERUEL & 76 & 32 \\
\hline TOLEDO & 361 & 4 \\
\hline VALENCIA & 2.865 & 120 \\
\hline VALLADOLID & 500 & 75 \\
\hline ZAMORA & 151 & 138 \\
\hline ZARAGOZA & 1.882 & $\mathbf{5 . 8 5 5}$ \\
\hline TOTAL & $\mathbf{6 4 . 2 6 7}$ & \\
\hline
\end{tabular}

Fuente: Ministerio de Fomento (2017)

Completando lo anteriormente expuesto, no hay que obviar la acción de algunas Comunidades Autónomas en el otorgamiento de las autorizaciones VTC. Si bien muchas de ellas acogen la regla de proporcionalidad (vid. Canarias en el art. 79 quinquies de la Ley 13/2007, de 17 de mayo, de transporte o la Resolución de 15 de diciembre 1998, de criterios de provincialización del cupo de autorizaciones de vehículos de arrendamiento con conductor en Andalucía), también es posible identificar la modificación de dicha regla por algunas de ellas, dentro de su ámbito territorial, y cumpliendo, eso sí, la premisa de ser menos restrictiva tal y como dispone el art. 181.3 ROTT.

Sobre todo, conviene atender a la regulación dada en Islas Baleares, en donde se establecen proporciones diferentes a través Decreto 43/2014, de 3 de octubre, que desarrolla y concreta determinados aspectos de la actividad de arrendamiento de vehículos con conductor en el ámbito territorial de las Illes Balears. En concreto estas proporciones se dividen por islas, siendo en Mallorca 12,6 VT por 1 VTC; Ibiza: 6,74 VT por 1 VTC, y Menorca: 17,33 VT por 1 VTC ${ }^{14}$. Dichas cifras hay que ponerlas en relación con el antiguo art. 14.1, tanto del Orden de 30 de julio de 1998, como de la Orden FOM/36/2008, de 9 de enero en el que se permitía alterar la regla de proporcionalidad mediante la elaboración y aprobación un plan o programación de transporte. En este sentido, en Baleares conviven dos Planes de adjudicación de autorizaciones de arrendamiento de vehículos con conductor (Ibiza y Menorca) que articulan las alteraciones de la regla de proporcionalidad. Así, el Plan de adjudicación de la Isla de Menorca, aprobado por el pleno del Consell el 26 de junio de 2006, basa la alteración en el hecho de un desajuste entre la oferta y la demanda, más cuando Menorca no disponía de ninguna autorización de vehículos de alquiler con conductor. Mismo planteamiento recogió la Resolución del Consejero de Medio Ambiente y Movilidad por la que se aprueba el Plan de adjudicación de autorizaciones de arrendamiento de vehículos con conductor en la isla de Ibiza

14 En el caso de la Comunidad Valenciana, la Resolución de 11 de abril de 2002, también incluye limitaciones en el número de autorizaciones estableciendo un número máximo de 149 autorizaciones de arrendamiento de vehículos con conductor (Alicante, 38 autorizaciones; Castellón: 38 autorizaciones y Valencia: 73 autorizaciones), número lejano al que se recoge en la tabla 1 a fecha de septiembre de 2017. 
REALA. Nueva Época - N. 9 9, Abril 2018 - ISSN: 1989-8975 - DOI: 10.24965/reala.v0i9.10470 - [Págs. 128-147]

El arrendamiento de vehículos con conductor (VTC) y su entramado jurídico: el avance de Uber, Cabify y la economía colaborativa

Nicolás Alejandro Guillén Navarro

de 12 de enero de 2011, justificando dicha alteración en la desproporción entre la oferta y la demanda a consecuencia de la gran actividad turística, en especial en época estival. No obstante, estas decisiones no han estado libres de polémica ya que ambas fueron recurridas ante el Tribunal Superior de Justicia de Islas Baleares, la primera por la Asociación Radio Taxi-Mahón y la segunda por la Confederación del taxi de España, precisamente por no respetar la regla de proporcionalidad de 1 autorización VTC por cada 30 taxis. El Tribunal, en ambos casos rechazó las pretensiones al entender que había una manifiesta desproporción entre la oferta y la demanda y que estaba perfectamente motivada por la Administración mediante sendos estudios técnicos (vid. sentencia núm. 50/2014, de 5 febrero). De todas maneras, si se acude a la redacción actual del art. 181.3 in fine ROTT, la posibilidad de modificar la regla de proporcionalidad, siempre que la que apliquen sea menos restrictiva, justificaría estas alteraciones, más cuando la norma no exige justificación, como sí que se requería antes.

Además del caso Balear, en otras Comunidades Autónomas también se pueden encontrar limitaciones ${ }^{15}$. Como caso reciente, Aragón cuenta con criterios marcados habiendo una evolución al respecto. Si en la Resolución de 26 de marzo de 2008, de la Dirección General de Transportes, establecía la ratio de cuatro VTC por cada cincuenta VT ${ }^{16}$, a través de la Orden VMV/845/2017, de 9 de junio, se derogó la anterior resolución volviendo al criterio normalizado del art. 181.3 ROTT. En el caso del País Vasco, la Orden de 11 de febrero 2005, por el que se establece el número máximo de autorizaciones de transporte público interurbano de viajeros en automóviles, también recoge cupos de autorizaciones de ámbito estatal para la prestación de servicios de arrendamiento de vehículos con conductor, estableciendo como límites 6 en Álava, 27 en Bizkaia, 15 en Gipuzkoa. Teniendo presente estos límites, la norma recoge asimismo que el número de autorizaciones no puede superar el $2 \%$ del número máximo de autorizaciones de transporte público interurbano de viajeros en automóviles de turismo resultante para cada Territorio Histórico (art. 6); no obstante, si se compara con los datos de la tabla 1 se da cuenta de la acción de los tribunales anteriormente apuntada al superarse con creces, por ejemplo, en Álava estos máximos.

\section{2. Ámbito de actividad, vehículos y signos distintivos}

Habiéndose delimitado las restricciones numéricas relativas a la concesión de nuevas licencias, conviene ahora analizar los requisitos y especificaciones que debe cumplir el solicitante de una autorización de arrendamiento de vehículos, los cuales se asocian a los artículos 43.1 LOTT, 181 y 182 ROTT, y que aquí se dividen en dos bloques para facilitar su exposición.

En primer lugar debe resaltarse el hecho de que la autorización VTC habilita para la realización de servicios, tanto urbanos como interurbanos, en todo el territorio nacional, habiendo una autorización individual para cada vehículo. No obstante, esta habilitación debe ser matizada con lo dispuesto en el art. 182.5 ROTT, precepto introducido por el art. 5 del Real Decreto 1057/2015, de 20 de noviembre. Dicho artículo introduce una delimitación territorial de la actividad al obligar a que al menos el $20 \%$ de los recorridos efectuados trimestralmente se realicen en la Comunidad Autónoma en que se haya concedido la licencia, por lo que, lógicamente, el vehículo VTC debe atender con ello a las necesidades del territorio de la Comunidad Autónoma en que se encuentre domiciliada la autorización en que se amparan. Como se ha señalado anteriormente, en Cádiz, Las Palmas y Santa Cruz de Tenerife, de acuerdo con los datos del Ministerio de Fomento se vienen distinguiendo entre VTC Nacional y VTC autonómico como clases de autorizaciones dentro del VTC. A ello hay que sumar ciertas acotaciones autonómicas, como la recogida en Islas Baleares en donde se vincula la antigüedad del vehículo, indicándose que aquellos que excedan de ocho años de antigüedad, contados

15 Caso complejo es el recogido en la Resolución de 12 de enero 2004, por el que se establece los criterios que regirán en la Comunidad Autónoma de Galicia para el otorgamiento de autorizaciones de alquiler de vehículos con conductor al amparo de la disposición adicional segunda de la Orden Ministerial de 30 de julio de 1998, por el que se establece una 1 empresa por cada 85.000 habitantes de derecho y autorizaciones adicionales para agregar a alguna de las empresas, a razón de un vehículo cada fracción completa de 30.000 habitantes de derecho. Asimismo, se indica que la solicitud inicial deberá, en todo caso, referirse a cinco vehículos por empresa (art. 4).

16 Entre las razones que justificaron en su momento la alteración de la regla de la proporcionalidad, se aludía a la desproporción entre la oferta y la demanda de esta clase de arrendamiento ante el «fuerte crecimiento, impulsado en gran medida desde el Gobierno de Aragón y que se ha materializado en forma de importantes plataformas logísticas, que albergan grandes centros empresariales, así como una diversidad de servicios de todo orden y, en especial, de carácter turístico, con una mejora progresiva de las comunicaciones que favorecen la ubicación empresarial en función de las específicas necesidades a lo largo de todo el territorio» (Resolución de 26 de marzo de 2008, de la Dirección General de Transportes, por la que se fijan las condiciones cuantitativas para el otorgamiento de autorizaciones de arrendamiento de vehículos con conductor). 
REALA. Nueva Época - N. 9 9, Abril 2018 - ISSN: 1989-8975 - DOI: 10.24965/reala.v0i9.10470 - [Págs. 128-147]

El arrendamiento de vehículos con conductor (VTC) y su entramado jurídico: el avance de Uber, Cabify y la economía colaborativa

Nicolás Alejandro Guillén Navarro

desde su primera matriculación, no podrán prestar ningún servicio de esta clase fuera de esta Comunidad Autónoma (art. 2 del Decreto 43/2014, de 3 de octubre).

De todos modos, el control de la habitualidad de los servicios vinculado a un ámbito geográfico de actividad ha sido un tema criticado por el sector del taxi. Tal es así que ha sido tratado dentro de las últimas modificaciones normativas sobre el VTC. A este respecto, el Real Decreto 1076/2017, de 29 de diciembre, por el que se establecen normas complementarias al Reglamento de la Ley de Ordenación de los Transportes Terrestres, en relación con la explotación de las autorizaciones de arrendamiento de vehículos con conductor, introduce una interesante medida destinada a garantizar estas limitaciones como es la habilitación por parte de la Dirección General de Transporte Terrestre de un registro de comunicaciones de los servicios de arrendamiento de vehículos con conductor, al que los titulares de las autorizaciones deberán dirigir sus comunicaciones (art. 2) y a través del cual se dará cuenta del cumplimiento de las limitaciones anteriormente señaladas.

En cuanto a la regulación de las características de los vehículos, el ROTT contiene diversos condicionantes como los relativos a las características (motor, longitud) ${ }^{17} \mathrm{o}$ antigüedad máxima de los vehículos (10 años), siempre partiendo de una capacidad máxima de 9 plazas incluida la del conductor (art. 181 ROTT). El límite de 10 años hay que matizarlo ya que se incluyen excepciones cuando la potencia fiscal sea igual o superior a 28 CVF o se trate de un vehículo histórico. Además, dentro de las regulaciones autonómicas se pueden encontrar diferentes acotaciones, aparte de la ya apuntada en Islas Baleares sobre el ámbito de actividad de los vehículos de más de ocho años,

Dentro de las características y elementos asociados a los vehículos conviene apuntar la incidencia del hecho de la prohibición de que los vehículos VTC tengan signos externos de identificación que induzcan a confusión con la actividad de los taxis (182.4 ROTT). A pesar de ello, distintas Comunidades Autónomas han regulado modelos identificativos como es el caso de Andalucía, Cataluña, Comunidad de Madrid o Islas Baleares ${ }^{18}$. Todas ellas recogen el modelo que deben incorporar los vehículos, si bien se identifican ciertas discrepancias en lo referido a la colocación, tamaño o contenido. Si en Aragón o la Comunidad de Madrid se opta porque el distintivo se encuentre tanto en la parte superior derecha de la luna delantera, como en la parte inferior izquierda de la luna trasera del vehículo, Andalucía e Islas Baleares optan por soluciones diferentes ya sea por su incorporación en la parte superior derecha de la luna delantera (Andalucía) o parte inferior derecha del parabrisas delantero del vehículo (Baleares). Mismo ocurre con el contenido, destacando el modelo andaluz que incorpora la indicación de la matrícula del vehículo y del mes y año en que ha de ser objeto el próximo visado, o el modelo balear que incluye un código QR identificador del vehículo autorizado ${ }^{19}$.

\subsection{Disposición de vehículos, número de conductores, trasmisión de licencias y hoja de ruta}

Otro bloque de requisitos vinculados con la solicitud de la autorización VTC son los referidos a la disposición de vehículos, número de conductores, la trasmisión de licencias y la importancia de la hoja de ruta como elemento articulador de la actividad.

Respecto al número de vehículos, el art. 181.2 ROTT, tras la modificación de 2015, establece que las empresas dedicadas a la actividad de arrendamiento con conductor han de disponer en todo momento, en

17 EI ROTT recoge diversas prescripciones en cuanto a la motorización y medidas, señalándose que el vehículo debe tener, como mínimo, un motor con una potencia igual o superior a 12 caballos de vapor fiscales (CVF) y una longitud mínima exterior igual o superior a 4,60 metros, condicionantes que se exoneran en el caso de que el vehículo utilice energías alternativas (art. 181.2).

18 Andalucía (Orden de 31 de marzo de 2017, por la que se regula el uso de un distintivo obligatorio para los vehículos de alquiler con conductor autorizados en la Comunidad Autónoma de Andalucía); Aragón (Orden VMV/898/2017, de 15 de junio, por la que se aprueba el distintivo identificativo de los vehículos destinados al arrendamiento de vehículos con conductor cuya autorización se encuentre residenciada en la Comunidad Autónoma de Aragón), Cataluña (Decreto-ley 5/2017, de 1 de agosto, de medidas urgentes para la ordenación de los servicios de transporte de viajeros en vehículos hasta nueve plazas); Comunidad de Madrid (Decreto 101/2016, de 18 de octubre, del Consejo de Gobierno, por el que se regulan los distintivos identificativos de los vehículos dedicados al arrendamiento de vehículos con conductor cuya autorización se encuentre residenciada en la Comunidad de Madrid) o Islas Baleares (Decreto $58 / 2016$, de 16 de septiembre, por el que se regula el distintivo de identificación de los vehículos dedicados a la actividad de arrendamiento con conductor en la comunidad autónoma de las Illes Balears).

19 De igual manera hay que indicar la tipificación, como infracción, el realizar la actividad de arrendamiento de vehículos con conductor mediante vehículos que lleven publicidad o signos externos identificativos, salvo en los supuestos reglamentariamente exceptuados, hecho que se recoge, por ejemplo, en el art. 99.2.g. de la Ley 6/2011, de 1 de abril, de Movilidad de Comunidad Valenciana, que lo considera como infracción leve en relación con los servicios de transporte de viajeros, sancionable con apercibimiento o multa de hasta 1.000 euros. 
REALA. Nueva Época - N. 9 9, Abril 2018 - ISSN: 1989-8975 - DOI: 10.24965/reala.v0i9.10470 - [Págs. 128-147]

El arrendamiento de vehículos con conductor (VTC) y su entramado jurídico: el avance de Uber, Cabify y la economía colaborativa

Nicolás Alejandro Guillén Navarro

propiedad o arrendamiento financiero, de al menos siete vehículos dedicados a esta actividad, cifra que aumenta respecto a los cuatro fijados por la modificación del ROTT en 2010. No obstante, estos mínimos también se referenciaban en la Orden FOM/36/2008, de 9 de enero, donde la redacción del art. 10 ha sufrido una evolución transitando del mínimo de 10 vehículos en su redacción original, mantenida en la modificación de 2011, a la derivación a lo dispuesto en el artículo 181.2 ROTT ${ }^{20}$. Sobre estos cambios se aprecia a su vez una falta de adaptación de las normativas autonómicas. Es el caso de Canarias, donde se exige un mínimo de 10 vehículos (art. 105 del Decreto 72/2012, de 2 de agosto, por el que se aprueba el Reglamento de Ordenación de Transporte por Carretera), si bien hay delimitaciones para el arrendamiento de vehículos con conductor de ámbito estrictamente insular. Así en las islas de El Hierro y La Gomera se pueden otorgar autorizaciones para el arrendamiento de vehículos con conductor de ámbito estrictamente insular con un mínimo de dos vehículos, siendo el mínimo de tres en el caso de La Palma.

Medida en su momento pensada para restringir el auge de las licencias VTC, parece que los mínimos en cuanto a disposición de vehículos poco efecto han tenido, aún más cuando empresas como UBER o Cabify aglutinan gran número de ellas, en parte favorecidas por el hecho de que el art. 181.2 ROTT establezca un amplio abanico de posibilidades de cara a lograr ese mínimo de vehículos ${ }^{21}$. No obstante, sí que es verdad que hay que hacer una matización y es que el Decreto de 2015 incorpora una disposición transitoria única por la que los titulares de autorizaciones de arrendamiento de vehículos con conductor vigentes en el momento de entrada en vigor de dicha norma que no dispusieran de este número mínimo de vehículos pudieran continuar el ejercicio de su actividad sin cumplir ese requisito en tanto que tales autorizaciones continuaran a su nombre. También hay que reseñar, como diferencias con el ámbito del taxi, el que los precios de la actividad de arrendamiento de vehículos con conductor no están sujetos a tarifa administrativa, si bien sí que existe obligación de que las correspondientes empresas deban tener a disposición del público información de las mismas (art. 3 del Real Decreto 1057/2015, del 20 de noviembre y 182.3 ROTT).

Vinculado a los vehículos se encuentra lo relativo a los conductores. En cuanto a este aspecto, dentro de la normativa se identifica una evolución normativa. La Orden de 2008 en su redacción original recogía en su art. 12 la obligación de que las empresas dispusieran de un mínimo de dos conductores por cada tres autorizaciones que se poseyeran, indicándose además el que se precisara un conductor adicional cuando la división del número de autorizaciones entre tres arrojara un resto superior a uno. El art. único.6 de la Orden FOM/2799/2015, de 18 de diciembre, modificó dicho precepto eliminando estos mínimos e introduciendo como únicas obligaciones el que los conductores se encuentren encuadrados en la organización empresarial y posean el permiso de conducción correspondiente.

Otro elemento destacado del régimen de autorizaciones del VTC es el relativo a la trasmisión de las autorizaciones, que cuenta con mínimos condicionantes restrictivos. Como excepción se encuentra el hecho de que la novación subjetiva no puede suponer la domiciliación de la autorización en una Comunidad autónoma distinta a aquélla en que originariamente se obtuvo, siempre teniendo en cuenta que el nuevo titular debe cumplir con todos los requisitos que marca la normativa en cuanto acreditación de la personalidad jurídica y nacionalidad de la empresa, cumplimiento de obligaciones fiscales y obligaciones laborales y sociales, o el número mínimo de vehículos (art. 20 de la Orden FOM/36/2008, de 9 de enero). Respecto a este último hecho, hay que matizar que las trasmisiones de autorizaciones anteriores a la entrada en vigor del Real Decreto 1057/2015, de 20 de noviembre, cuentan con el beneficio de la inexigibilidad de flota mínima cuando la transmisión tenga por objeto la totalidad de autorizaciones de que sea titular el cedente y se realice a favor de un único adquirente (Disposición transitoria única). De todos modos, el Real Decreto 1076/2017, de 29 de diciembre, ha introducido otro requisito más como es el que las autorizaciones VTC no puedan ser transmitidas hasta que hayan transcurrido dos años desde su expedición original por el órgano competente en materia de transporte terrestre, salvo en los supuestos de transmisión a favor de herederos en los casos de muerte, jubilación por edad o incapacidad física o legal de su titular (art. 1).

${ }^{20}$ Enlazado con este aspecto hay que aludir de igual manera a la disponibilidad de local, si bien este hecho se recogía en el art. 9 de la Orden FOM/36/2008, de 9 de enero, fue suprimido por el art. único.3 de la Orden FOM/2799/2015, de 18 de diciembre. En dicho precepto se venía exigiendo la disponibilidad de un local en el municipio donde se encuentren domiciliados los vehículos, el cual debía ser distinto al domicilio privado de su titular. Esta obligación se ha mantenido en regulaciones autonómicas, como es el caso de Galicia donde se recoge como requisito para desarrollar la actividad (arts. 47 y 55 de la Ley 4/2013, de 30 de mayo, de transporte), el cual debe estar dedicado en exclusiva a dicha actividad y no podrá ser compartido por varias empresas.

${ }_{21}$ Así, la empresa Uber dispone en su web la posibilidad de registrarse como conductor, dando la posibilidad de utilizar su propio coche, siempre que cumpla los requisitos tasados entre los cuales se encuentran el que esté registrado y asegurado. 
REALA. Nueva Época - N. 9, Abril 2018 - ISSN: 1989-8975 - DOI: 10.24965/reala.v0i9.10470 - [Págs. 128-147]

El arrendamiento de vehículos con conductor (VTC) y su entramado jurídico: el avance de Uber, Cabify y la economía colaborativa

Nicolás Alejandro Guillén Navarro

Para finalizar, conviene apuntar la importancia de la hoja de ruta, criterio esencial y que marca la actividad del VTC. En este sentido, el art. 24 de la Orden FOM/36/2008, de 9 de enero, exige cumplimentar una hoja de ruta por cada servicio con la obligación de conservar la misma durante el plazo de un año, contado a partir de la fecha de celebración del contrato, con objeto de control administrativo. En dicha hoja deben consignarse toda una serie de datos como los del arrendador y el arrendatario o el trayecto que se ha realizado. Esta circunstancia debe ponerse en correlación con el hecho de que la contratación de los servicios debe realizarse de manera de previa, por lo que cualquier movimiento del coche vendrá condicionado a su existencia.

\section{EL SECTOR DEL TAXI FRENTE LA ECONOMÍA COLABORATIVA Y LOS VTC}

Sin duda la llamada economía colaborativa ha roto el modelo clásico de transporte, dando paso a plataformas $p 2 p$ como Uber, Cabify o Blablacar que reorganizan la oferta y demanda de los servicios de transporte terrestre. Su efecto sobre el transporte es claro y dista mucho del origen del concepto centrado simplemente en compartir bienes y servicios entre varios usuarios con el fin de maximizar los recursos disponibles ${ }^{22}$.

La economía colaborativa se basa en la producción de servicios entre redes de personas que a su vez se convierten en consumidores. Aunque existen muchas delimitaciones, hay que considerar que este modelo económico pasa por el hecho de que el consumidor adquiere el papel de proveedor de servicios en un mundo virtual ${ }^{23}$. A ello debe añadirse otro elemento importantísimo como es la confianza dentro de los miembros de la comunidad, sumada a la reputación del usuario que ofrece su bien ${ }^{24}$. De todas maneras, hay que advertir que el modelo clásico de economía colaborativa ha muerto en favor de un modelo mixto en el que existe una motivación comercial y un trasfondo económico que desvirtúan la finalidad «colaborativa» de esta nueva corriente económica ${ }^{25}$.

En este marco, las plataformas $p 2 p$ juegan a ser las abanderas de la economía colaborativa y en donde la idea básica de «compartir» da paso al beneficio económico de empresas intermediadoras que tienen como herramienta internet y que juegan con las necesidades de los consumidores. La indefinición acerca de la actividad que realizan da lugar a un vacío legal en el que basan su actuación y que enfrenta a sectores regularizados que operan bajo las autorizaciones pertinentes. Este es el caso del conflicto del sector del taxi con Uber y Cabify con una incursión de estos últimos en la prestación de servicios de transporte urbano escudada en el principio de libre prestación de servicios, un aspecto roto por completo a través de diversos pronunciamientos judiciales como se verá más adelante ${ }^{26}$.

En el ámbito de la Unión Europea, tanto la Comisión Europea (2016), el Comité Económico y Social Europeo (2016) y el Comité Europeo de las Regiones (2017), aunque alaban los beneficios de la economía colaborativa, ponen énfasis en la necesidad de que los Estados miembros creen un marco regulatorio adecuado evitando con ello los ámbitos de ilegalidad y, sobre todo, garanticen una protección a los usuarios ante el avance de las plataformas $p 2 p$.

En el transporte, la interrupción de las plataformas se ha debido no sólo a los cambios tecnológicos, sino esencialmente a una ausencia de regulación, hecho que se ha sido aprovechado por las mismas para situarse en una posición destacada y a la vez enfrentada directamente con un sector consolidado y regularizado como es el del taxi. Aunque la postura del sector del taxi deriva a la existencia de una competencia desleal por parte de estas plataformas, no todos los agentes ven esta situación, derivando incluso la situación hacia otras opiniones totalmente contrarias y que identifican una clara restricción a la expansión del VTC.

22 FELSON Marcus y SPAETH Joe (1978), ALGAR (2007) y BOTSMAN Y ROGERS (2010). Como expone DURÁN SÁNCHEZ et al. (2016) a su vez se han generado conceptos en paralelo como «new economy» (Delong \& Summers, 2001), "sharing economy» (Lessig, 2008), «collaborative consumption» (Algar, 2007), «peer-to-peer economy» (RODRIGUES \& DRUSCHEL, 2010), «gig economy» (FRIEDMAN, 2014), «disaggregate economy» (RAUCH \& SCHLEICHER, 2015) o «access economy» (DENNING, 2014).

${ }^{23}$ Cabe destacar, por ejemplo, la definición dada por la COMISIÓN EUROPEA (2016) en un documento denominado Agenda Europea para la economía colaborativa, la cual asocia a «modelos de negocio en los que se facilitan actividades mediante plataformas colaborativas que crean un mercado abierto para el uso temporal de mercancías o servicios ofrecidos a menudo por particulares».

24 Vid. BOTSMAN Y ROGERS (2010), RUSSO (2015) y RUSSO y QUAGLIERI DOMÍNGUEZ (2014).

25 Vid. BELK (2013 y 2014), MOLZ (2012) y RUSSO (2015).

${ }^{26} \mathrm{La}$ incidencia de la economía colaborativa en el ámbito del transporte ha sido analizada por la doctrina teniendo como eje central los efectos de la incursión de Uber en este sector. Como estudios se pueden destacar los de BOBOC (2017); CONTRERAS DELGADO DE COS et al. (2017); DOMÉNECH PASCUAL (2015. 2016 y 2017); GÓRRIZ LÓPEZ (2015); JARNE MUÑOZ (2015 y 2016), LEIÑENA MENDIZÁBAL (2015) LÓPEZ-IBOR et. Al. (2017) y OLMEDO PERALTA (2017). 
Este es el caso de la postura de la Comisión Nacional de los Mercados y la Competencia (CNMC), la cual no ha ocultado su apoyo al sector del VTC a través de una oposición a la normativa del arrendamiento de vehículos con conductor, de la que extrae un marco restrictivo asociado al simple hecho de «blindar y mantener un régimen de monopolio en el sector del taxi». En relación con este aspecto, la CNMC emitió un informe económico en junio de 2016 acerca de las restricciones a la competencia, centrándose en los efectos de la regla $1 / 30$ y el modelo de pre-contratación del servicio asociado al VTC ${ }^{27}$.

Este informe económico parte de la existencia de un claro monopolio del taxi, además de numerosas restricciones a la competencia. Teniendo en cuenta estos aspectos, el documento dedica especial atención a los efectos que produce la regla de proporcionalidad 1/30, asociando directamente una reducción de la rivalidad entre los operadores. En cuanto a la incidencia de la restricción del sector VTC al segmento de pre-contratación del servicio, el pronunciamiento de la CNMC es muy claro al entender que si eliminaran estas restricciones, véase la prohibición de captar pasajeros en la calle o la obligación de contratar la capacidad total del vehículo, los precios se «reducirían y la calidad, la variedad y la innovación en la prestación del servicio aumentaría». Con ello, la CNMC apuesta claramente por la plena libertad de precios en el transporte urbano de pasajeros por taxi/VTC, además de eliminar las barreras para que los VTC puedan captar clientes, ya que de ello puede contribuir a reducir el tiempo de espera de los clientes, aumentando así su «bienestar».

Por otra parte, las limitaciones apuntadas por la CNMC no se quedan ahí sino que también se expanden al impacto del establecimiento de un número mínimo y requisitos de los vehículos, además de las restricciones geográficas en la prestación del servicio. En cuanto a las primeras restricciones, la CNMC señala que estas medidas suponen incremento de los costes, reduciendo así «el número de competidores que el mercado puede acomodar y contribuye de este modo a limitar la competencia». Por lo que respecta a las limitaciones geográficas, también hay una oposición ya que obstaculiza la entrada de operadores en cualquier mercado del territorio nacional y dificulta el que los «operadores puedan competir en un mercado distinto al de origen y limita que puedan rentabilizar un trayecto originado en su Comunidad Autónoma de origen y con destino a una Comunidad».

La lucha entre el VTC y el taxi es claramente económica. En este sentido, un aspecto básico para entender esta problemática es el valor que tiene una licencia de taxi y una licencia VTC. Sobre este aspecto, los derechos exclusivos que tienen los taxis de cara al usuario, véase la recogida de usuarios en la calle o la disposición de paradas, conlleva un menor valor de la licencia VTC en el mercado secundario. No obstante, el hecho de la posibilidad de adquirir una licencia de VTC al mero coste administrativo de expedición, sin acudir al mercado secundario, facilita el que se produzca una reducción las tarifas, dando con ello un juego competitivo que puede arrastrar al sector del taxi a bajar también sus tarifas ${ }^{28}$.

Sin duda, los efectos proteccionistas sobre el sector del taxi carecen de todo sentido desde el punto de vista competencial, más cuando el auge de las nuevas tecnologías deriva a un nuevo replanteamiento normativo del transporte, rompiendo con ello las barreras a las autorizaciones VTC en aras de favorecer un equilibrio entre medios de trasporte del que salga beneficiado el conjunto de los usuarios al aumentarse la disponibilidad de prestadores del servicio, reduciendo así los tiempos de espera y una rebaja de las tarifas. Asimismo, desde las posturas favorables al VTC se extrae ya no sólo un impacto económico positivo en la supresión de las barreras al VTC, sino también efectos positivos sobre el sistema de movilidad (intermodalidad), así como ahorros medioambientales ${ }^{29}$.

Sobre este último aspecto, el conflicto entre el VTC y el taxi también está presente sobre todo en el hecho de la circulación de ambos tipos de vehículos ante restricciones de tráfico por episodios de contaminación.

Para entender esta problemática, conviene atender a la sentencia 317/2017 del Juzgado de lo contencioso administrativo núm. 10 de Madrid en donde se pone de manifiesto la equiparación de los VTC y los taxis a la hora de circular durante los episodios de alta contaminación por dióxido de nitrógeno en la Capital, poniendo a un mismo nivel ambos transportes ante la aplicación de las medidas de restricción del tráfico y del estacionamiento recogidas en el Protocolo aprobado por acuerdo de la Junta de Gobierno del Ayunta-

${ }_{27}$ CNMC (2016). En concreto dicho informe se asocia directamente a los efectos competenciales del Decreto 1057/2015, de 20 de noviembre, de modificación del ROTT y la Orden FOM/2799/2015, de 18 de diciembre, por la que se modifica la Orden FOM/36/2008, de 9 de enero.

28 AFI (2017).

29 Vid. AFI (2017) y CNMC (2016). 
miento de Madrid el 21 de enero de $2016^{30}$. La sentencia parte de la argumentación de la parte recurrente de la existencia de una restricción indebida de la circulación de los VTC en el Decreto impugnado, considerándose además un trato desigual frente a los taxis, los cuales ante la aplicación del nivel 3 tienen libre circulación, sin que les afecte prohibición o limitación alguna ${ }^{31}$. La sentencia rechaza la argumentación del Ayuntamiento en cuanto a la existencia de diferencias en cuanto a su regulación y condiciones de prestación del servicio de los taxis y los VTC y mucho menos el argumento de que los autotaxis estén sometidos a un régimen de limitación de emisiones contaminantes y de antigüedad máxima del vehículo que los VTCs no tienen que cumplir. Con ello, con base en la inexistencia de diferencias a efectos contaminantes, el Tribunal resuelve en favor de la mencionada equiparación.

Para finalizar, los efectos competenciales de los VTC no sólo han sido analizados en el ámbito estatal. En este sentido, la Autoridad Catalana de la Competencia (2017) a través de su informe IR 31/2017, de 4 de septiembre de 2017, ha entrado también en el asunto a través de la valoración del Decreto Ley $5 / 2017$, de 1 de agosto, de medidas urgentes para la ordenación de los servicios de transporte de viajeros en vehículos hasta nueve plazas, en cuanto a si dicha norma introduce restricciones a la competencia. Sobre este aspecto, el ente en sus conclusiones aboga por incentivar una mayor competencia entre taxis y VTC a través de la libre operación en los diferentes segmentos de contratación del servicio, todo ello en igualdad de condiciones. Este planteamiento deriva ante una férrea defensa de la competencia en favor de un mayor beneficio para los usuarios, criticando la rigidez de la norma y en concreto medidas insertas como los límites en la transmisión de las autorizaciones de VTC (art. 1) o la obligación de los VTC de comunicar, vía registro electrónico, los servicios que han sido contratados con carácter previo a su prestación.

Como se comprueba, la incursión de Uber y Cabify en el transporte de pasajeros en el ámbito urbano, a través del VTC, va rompiendo barreras en aras de una progresiva equiparación con el sector del taxi a falta de la restricción en cuanto a la captación de pasajeros anteriormente aludida. No obstante, esta situación no siempre ha sido así, sobre todo en los orígenes de Uber en España y su paralización judicial a causa del modelo colaborativo que asumía y que se analizará a continuación.

\section{EL CONFLICTO CON UBER Y CABIFY}

Desde que Uber se instalara en España en 2014, su actividad ha estado siempre en el ojo del huracán. Con el colectivo del taxi a la expectativa, la deriva en cuanto a su funcionamiento en sus diversas modalidades ha sido también objeto de análisis en sede judicial.

A este respecto, Uber ha evolucionado transitando de la polémica Uber Pop a la actual Uber X, llave del regreso de Uber a España en 2016 desde que el Juzgado de lo Mercantil núm. 2 de Madrid en su Auto de 9 diciembre 2014 determinara con base en el artículo 15 de la Ley 3/1991, de 10 de enero, de competencia desleal, una afección a la competencia y el carácter de deslealtad de Uber al operar sin las preceptivas autorizaciones administrativas exigidas en el ámbito del servicio regular de transporte de viajeros. Este hecho estructuró la resolución y es que la utilización de una aplicación móvil que posibilitaba «un servicio de transporte de viajeros por parte de conductores sin la preceptiva licencia» (fundamento de derecho primero), suponía una actividad concurrencial ilícita, conllevando así la adopción de medidas cautelares y el fin de la actividad de Uber, de momento, en España.

Este pronunciamiento fue la línea de salida de otros centrados en lograr desentrañar la delimitación legal de esta plataforma. Como punto de partida cabe señalar dos sentencias del Juzgado de lo ContenciosoAdministrativo núm. 15 de Barcelona (Sentencias núm. 216/2016, de 6 octubre, núm. 287/2016, de 5 octubre y núm. 179/2016, de 18 julio) las cuales sirven para antesala a la resolución de la problemática.

${ }^{30}$ Pronunciamiento a raíz del recurso contencioso-administrativo interpuesto por UNAUTO VTC contra la Resolución del Ayuntamiento de Madrid que imposibilitaba la circulación de los vehículos de arrendamiento con conductor en la almendra central de Madrid por Decreto núm. 888, de 27 de diciembre de 2016, en concreto los vehículos con matrícula par.

31 Vid. fundamento jurídico segundo: «pero sin embargo, al arrendamiento de vehículos con conductor, que es un transporte de viajeros, no se le trata de manera igual que al taxi, hasta el punto de que no sólo no puede circular sin ocupación cuando sí lo permite su norma reguladora (artículo 182.11 del RD 1211/1990, de 28 de septiembre), sino que si se estaciona en una zona del SER con su conductor dentro del vehículo (nivel 2 también aplicable junto al nivel 3) no podría posteriormente circular por el interior de la almendra central de la ciudad de Madrid a recoger viajeros previamente concertados, máxime cuando los vehículos de arrendamiento con conductor tienen en la Ordenanza de Movilidad a la que se remite el Decreto impugnado el mismo trato que los auto-taxi». 
REALA. Nueva Época - N. 9 9, Abril 2018 - ISSN: 1989-8975 - DOI: 10.24965/reala.v0i9.10470 - [Págs. 128-147]

El arrendamiento de vehículos con conductor (VTC) y su entramado jurídico: el avance de Uber, Cabify y la economía colaborativa

Nicolás Alejandro Guillén Navarro

Tomando como modelo la sentencia núm. 216/2016, de 6 octubre, dichos pronunciamientos parten de la resolución del Director General de Transportes y Movilidad de la Generalitat de Cataluña que impuso a Uber una sanción por la «contratación como transportista o la facturación en nombre propio de servicios de transporte público discrecional de viajeros en vehículos de hasta 9 plazas sin ser previamente titular de autorización de transporte». Recurrida dicha sanción ante el Tribunal Superior, éste dio la razón a Uber al considerar que el servicio prestado le era de aplicación la Ley 34/2002, de 11 de julio, de Servicios de la Sociedad de la Información y de Comercio electrónico (LSSI) y no la LOTT ${ }^{32}$, todo por la existencia de un vacío legal en esta última norma al hablar de mediación en la prestación de servicios de transporte y no incluir una referencia al transporte de viajeros o personas (art. 122 LOTT) ${ }^{33}$.

Ante dicho pronunciamiento, la Letrada de la Generalitat de Cataluña preparó contra el mismo un recurso de casación, derivando con ello su trámite ante el Tribunal Supremo que, como primer paso, admitió el mismo y dictó Auto de 13 marzo 2017 a expensas de su pronunciamiento mediante sentencia. En dicho Auto ya se podían extraer ciertos elementos como la difícil tarea, a la par que necesaria, de determinar si la actividad de Uber se enmarca en «el ámbito de la normativa de transportes -que exige el previo título habilitante para su ejercicio- o si, por el contrario, sus particulares características la sitúan en el ámbito de la LSSI y, en última instancia, en el ámbito de la Directiva de Servicios, en el que la premisa de partida es el libre establecimiento y la libre prestación de servicios».

Teniendo en cuenta estos antecedentes, el Tribunal Supremo en sentencia núm. 87/2018, de 25 enero, ha aclarado dicha situación, resolviendo por tanto una discrepancia que lleva latente desde que empezaran las actividades de Uber en España. La respuesta es sencilla y es que aprovechando la sentencia del Tribunal Superior de Justicia de la Unión Europea de 20 de diciembre de 2017, la cual es analizada en este apartado, dictamina que la actividad que desarrolla Uber ha de calificarse de «servicio en el ámbito de los transportes».

Sí que es verdad que la versión de Uber ha evolucionado, adoptando un modelo que trata de apaciguar el revuelo jurídico planteado ante la indefinición de su actividad, huyendo así de la base colaborativa sobre la que se asentaba. Ello ha llevado a la aparición de Uber X, una aplicación que, como digo, poco tiene que ver que su predecesora Uber Pop. En este sentido, Uber $X$ opera gracias a conductores profesionales que disponen de su respectiva licencia de VTC, modelo diferente del seguido a través de Uber Pop, basada en el llamado ride-sharing, poniendo así límites a la acción de particulares en la prestación de servicios de transporte en las ciudades españolas. A ello debe sumarse la existencia, aunque no implantada en España, de Uber Pool a través de la cual se puede compartir el viaje con varias personas que están en la misma ruta.

Si en España Uber ha tenido serios problemas en el desarrollo de su actividad, fuera de nuestras fronteras también ha encontrado serios obstáculos ${ }^{34}$. Caso sin duda interesante es la retirada por parte de la Autoridad de transporte de Londres de la autorización a Uber para operar en sus calles, lo que es un claro ejemplo más de la reticencia de las Administraciones de dar vía libre al pleno desarrollo del arrendamiento de vehículos con conductor. No obstante, resulta curioso que la denegación se deba esencialmente a motivos que la Autoridad de transportes aduce que afectan negativamente a la seguridad de los usuarios, lejos por tanto de la temática concurrencial (Transport for London, 2017).

32 Acerca de la incidencia de la Ley 34/2002, de 11 de julio, se pueden consultar los estudios de MAESTRE (2001), MUÑIZ ESPADA (2002), SOLA TEYSSIERE (2002), RIVERO GONZÁLEZ (2003) y VELEIRO REBOREDO (2002).

${ }_{33}$ Vid. Fundamento jurídico tercero de las sentencias: «Al respecto, se ha de partir de la premisa de lo que indica el art. $3.1 \mathrm{Ce}$ a cuya virtud, las normas jurídicas se interpretarán, entre otros criterios, según el sentido propio literal de sus palabras y según la realidad social del tiempo en que han de ser aplicadas, atendiendo fundamentalmente al espíritu y finalidad de aquéllas. Desde esta perspectiva, nadie discute que el art. 122 LOTT anterior a la reforma operada por Ley 9/13 hablaba de mediación en la prestación de servicios de transporte, pero lo centraba exclusivamente en la figura de las agencias de viaje (la actora pues, no es ni lo ha sido nunca una agencia de viajes), concepto éste que fue ampliado tras la reforma legal citada 9/13 a cualquier operador logístico o empresa especializada, para dar cabida a nuevas formas de mediación u organización en la prestación del servicio de transporte, pero el legislador, bien por olvido, bien expresamente, ha querido centralizar tal actividad llevada a cabo por operadores logísticos a transporte de mercancías (art. 122 LOTT), omitiendo cualquier referencia a transporte de viajeros o personas. Ante tal omisión o vacío legal, no cabe hacer una interpretación extensiva de la norma, máxime cuando nos hallamos ante una sanción administrativa, y por ende, ha de ser aplicada esta interpretación restrictiva en su aplicación práctica. En tal sentido, no podemos hablar de que la aquí demandante sea una operadora logística del art. 122 LOTT, ya que si así lo hubiera querido el legislador así lo habría hecho o dicho, y por el contrario, en la exposición de motivos de la Ley $9 / 13$ ya se nos habla de una liberalización plena en la intermediación en la contratación de transportes de viajeros. Tampoco cabe atribuir a la actividad llevada a término por la demandante como actividad clandestina, en terminología del art. 138.1.b) "in fine" LOTT, ya que aquélla está debidamente publicitada vía internet. De esta forma tenemos que, la normativa sancionadora a aplicar no es la LOTT, sino la Ley 34/2002 que, en su anexo, define lo que se entiende por servicios de la sociedad de la información».

${ }^{34}$ En este sentido, es interesante la exposición de RAUCH \& SCHLEICHER (2015). 
La retirada de la autorización es el último eslabón de problemáticas surgidas en Londres que se suma a otras como las restricciones en el servicio de los VTC en la ciudad y que fueron incluso fueron objeto de pronunciamiento judicial a nivel europeo. En este sentido, la Sentencia de 14 enero 2015 del Tribunal de Justicia de la Unión Europea (Sala Segunda) en el caso Eventech Ltd contra Parking Adjudicator analizó y se pronunció acerca de las limitaciones impuestas acerca de la utilización de los carriles bus de Londres a los vehículos VTC, cosa que se permitía a los taxis y que puede servir como modelo ante esta cuestión en España ${ }^{35}$. Dicha sentencia recoge un interesante análisis de las condiciones de autorización tanto de la licencia de taxi, como de VTC, si bien se centra en la problemática referida a la política por la que se autoriza a los taxis londinenses, pero no a los VTC salvo para recoger o dejar a pasajeros, a utilizar los carriles bus de los diferentes Boroughs de Londres durante las horas en que se aplican las limitaciones de circulación. Las ventajas de reservar un taxi en vez de un VTC en hora punta fue el hecho que se planteó en la sentencia y con ello la posible ventaja económica de los taxis a través la utilización de una infraestructura pública. La sentencia destaca por derivar su pronunciamiento a la delimitación de la figura del taxi y del VTC, en especial su estatuto jurídico, llegando a la conclusión que «los taxis londinenses y los VTC se encuentran en situaciones fácticas y jurídicas lo suficientemente distintas como para considerar que no son comparables y que, por tanto, la política relativa a los carriles destinados a los autobuses no confiere una ventaja económica selectiva a los taxis londinenses». Este planteamiento llevó como conclusión el que Tribunal se pronunciara por dar por buena esta limitación ya que no había que entender que se comprometieran fondos estatales ni que se confiera a los taxis una ventaja económica selectiva.

El coto a Uber en Londres no es el único obstáculo al cual se enfrenta la empresa en Europa ya que a ello hay que sumar los problemas surgidos en Dinamarca con el abandono de Uber de este país a principios de 2017 ante las exigencias de equipamiento en los vehículos marcadas por el Gobierno danés. Además, en julio de 2016 la empresa suspendió sus actividades en Hungría, ante la aprobación de una nueva normativa muy restrictiva con la actividad de Uber al contener el bloqueo técnico de los servicios de internet de cualquier proveedor de taxis sin central de llamadas.

En el ámbito de la Unión Europa, también existen claros pronunciamientos ante el avance de la aplicación Uber y su posicionamiento en el transporte, si bien en su origen se aprecia cierta discrepancia a la hora de enfocar dicha problemática.

Si en el informe encargado por la Comisión Europea a la consultora italiana Grimaldi Studio Legale sobre el sector del transporte urbano en los 28 estados miembros se destaca a España como uno de los países con mayores barreras a la entrada de nuevos agentes y por ende con mayores trabas a una eficiente competitividad ${ }^{36}$, en el ámbito judicial se ha dado un vuelco en el respaldo a este tipo de aplicaciones al delimitarlas en el ámbito del trasporte. En este sentido, en las conclusiones del abogado general, Maciej Szpunar, presentadas el 11 de mayo de 2017, en el caso Asunto C434/15 (Asociación Profesional Élite Taxi contra Uber Systems Spain, S. L.), se comprueba una posición clara ante esta plataforma.

El dilema planteado se centraba en si las prestaciones de Uber deben asociarse «al principio de libre prestación de servicios en tanto que servicios de la sociedad de la información» o si están incluidas en el ámbito del transporte regulado por el Derecho de los Estados Miembros. Una delimitación con importantes consecuencias, ya que sólo en el segundo caso los Estados miembros tendrían en principio libertad para regular su actividad.

Tras un análisis minucioso de Uber, el Abogado General llegó a la conclusión de que Uber debía calificarse de «servicio en el ámbito del transporte», no aplicándose por tanto el principio de libre prestación de servicios. Ello era debido, acudiendo a las palabras textuales del mismo, a que «la prestación de poner en contacto pasajero y conductor, facilitada por vía electrónica, ni es autónoma ni principal en relación con la prestación de transporte. Por ello, el servicio ofrecido por Uber no puede calificarse de servicio de la sociedad de la información: se trata más bien de la organización y gestión de un sistema completo de transporte urbano bajo petición» (Tribunal de Justicia de la Unión Europea, 2017).

Este pronunciamiento supuso el primer revés a Uber a nivel europeo, siendo preludio de la Sentencia sobre el caso que meses más tarde llegaría y que sigue parecidos planteamientos. La Sentencia de 20 diciembre 2017 del Tribunal de Justicia de la Unión Europea (Gran Sala) en el Caso Asociación Profesional

35 Tal y como se señala en la sentencia, en el caso de Londres la licencia de explotación de los VTC se expide de acuerdo con las disposiciones de la Private Hire Vehicles (London) Act de 1998. De igual manera que en España, los VTC no tienen el derecho de ofrecer sus servicios en Londres y por tanto sólo pueden recoger a personas que hayan contratado previamente sus servicios.

36 Vid. Comisión Europea (2016b). 
REALA. Nueva Época - N. 9 9, Abril 2018 - ISSN: 1989-8975 - DOI: 10.24965/reala.v0i9.10470 - [Págs. 128-147]

El arrendamiento de vehículos con conductor (VTC) y su entramado jurídico: el avance de Uber, Cabify y la economía colaborativa

Nicolás Alejandro Guillén Navarro

Elite Taxi contra Uber Systems Spain, S. L., constituye en el primer combate resuelto entre el sector del taxi y Uber en esta instancia con claras consecuencias en la delimitación de sus actividades al situar la actividad de Uber en el ámbito de los transportes.

Es verdad que el caso analizado dista bastante de la actividad actual de Uber en España y su vinculación a las licencias VTC ya que en la sentencia se habla de «servicio remunerado de conexión de conductores no profesionales que utilizan su propio vehículo y personas que desean realizar desplazamientos urbanos, sin disponer de permisos y licencias administrativas, para prestar dicho servicio». No obstante, lo interesante de la sentencia es la calificación jurídica del servicio de intermediación a través de medios informáticos prestado por Uber ${ }^{37}$. Con ello, de nuevo surge el dilema de si este servicio debe considerarse una mera actividad de transporte o ha de considerarse un servicio electrónico de intermediación o un servicio propio de la sociedad de la información en los términos que define el artículo 1.2 de la Directiva 98/34/CE del Parlamento Europeo y del Consejo, de 22 de junio de 1998, por la que se establece un procedimiento de información en materia de las normas y reglamentaciones técnicas y de las reglas relativas a los servicios de la sociedad de la información, con las correspondientes consecuencias asociadas al principio de libertad de prestación de servicios.

Analizando la actividad de Uber, el Tribunal parte de la circunstancia de que el servicio de intermediación crea una oferta de servicios de transporte urbano mediante herramientas informáticas dirigida a personas que quieren desplazarse por el ámbito urbano y por ende demandantes de este tipo de oferta. De igual manera, destaca el hecho de que Uber organiza la selección de conductores y ejerce, dice la Sentencia, una «influencia decisiva sobre las condiciones de las prestaciones efectuadas por estos conductores», en concreto el precio máximo de la carrera, la calidad de los vehículos o la idoneidad y el comportamiento de los conductores.

Todo ello parece basar la decisión del Tribunal que, con parecido planteamiento con las Conclusiones del Abogado General anteriormente descritas, considera que este servicio de intermediación no puede tener la calificación de «servicio de la sociedad de la información», debido a que es parte integrante de un servicio global cuyo elemento principal es un servicio de transporte. Este pronunciamiento se razona a través de la consideración de que el denominado "servicio en el ámbito de los transportes», atendiendo a la jurisprudencia comunitaria ${ }^{38}$, engloba no sólo los servicios de transporte como tales, «sino también cualquier servicio ligado de forma inherente a un desplazamiento de personas o mercancías de un lugar a otro gracias a un medio de transporte», circunstancia que aquí se presenta. Como consecuencia, el Tribunal rechaza la aplicación sobre la actividad de Uber de las Directivas 2000/31 (Directiva sobre el comercio electrónico) y 2006/123 (Directiva relativa a los servicios en el mercado interior), así como del artículo 56 del Tratado de Funcionamiento de la Unión Europea (TFUE), referido a la libre prestación de servicios en general ${ }^{39}$, para acoger en el presente caso el abrigo del artículo 58 TFUE (libre prestación de servicios, en materia de transportes) y aplicar la política común de transportes. No obstante, aún se profundiza más, ya que ante la ausencia de normativa comunitaria sobre esta materia, se añade una deriva hacia a los Estados Miembros, siendo los encargados de regular las condiciones de prestación de servicios de intermediación como el analizado y dejando claro que en todo caso esta actividad está «indisociablemente vinculado a un servicio de transporte y, por lo tanto, ha de calificarse de servicio en el ámbito de los transportes».

Si el conflicto con Uber es patente, no lo es menos con Cabify, la cual maneja gran número de autorizaciones VTC en España. Es verdad que la repercusión a nivel jurisprudencial es menor que con la otra plataforma, pero en el hecho de la problemática del conflicto VTC-taxi se sitúan a la par. El servicio ofrecido por esta compañía se basa en la prestación de un servicio de alquiler de vehículo con conductor a través de medios telemáticos, asignando un conductor con licencia VTC el cual está vinculado contractual con MAXI MOBILITY SPAIN, S. L., filial de Cabify en España, que es la que factura el importe del servicio al cliente, un servicio que se presta conforme a una hoja de ruta tal y como se ha explicado anteriormente. El modelo

37 En concreto, como dice la Sentencia, «intermediación entre el titular de un vehículo y la persona que necesita realizar un desplazamiento dentro de una ciudad, gestionando los medios informáticos -interfaz y aplicación de software, teléfonos inteligentes y plataforma tecnológica- que permitan su conexión»

38 Vid. Sentencia de 15 de octubre de 2015, Grupo Itevelesa y otros, C-168/14, EU:C:2015:685, apartados 45 y 46, y el dictamen 2/15 (Acuerdo de libre comercio con Singapur), de 16 de mayo de 2017, EU:C:2017:376, apartado 61].

39 Directiva 2000/31/CE del Parlamento Europeo y del Consejo, de 8 de junio de 2000, relativa a determinados aspectos jurídicos de los servicios de la sociedad de la información, en particular el comercio electrónico en el mercado interior (Directiva sobre el comercio electrónico) y Directiva 2006/123/ce del Parlamento europeo y del Consejo de 12 de diciembre de 2006, relativa a los servicios en el mercado interior. 
REALA. Nueva Época - N. 9 9, Abril 2018 - ISSN: 1989-8975 - DOI: 10.24965/reala.v0i9.10470 - [Págs. 128-147]

El arrendamiento de vehículos con conductor (VTC) y su entramado jurídico: el avance de Uber, Cabify y la economía colaborativa

Nicolás Alejandro Guillén Navarro

utilizado por Cabify se ha asentado por la utilización de esta modalidad de conductores, modelo que ahora asocia Uber a través de su aplicación Uber X.

El hecho de moverse fuera de la denominada economía sumergida al utilizar una opción legal como es el VTC ha conllevado el que el tratamiento jurisprudencial sea escaso. No obstante, la Sentencia núm. 159/2017 de 13 junio, del Juzgado de lo Mercantil núm. 12 de Madrid ha analizado la actuación de esta plataforma como consecuencia de la demanda interpuesta por la Federación profesional del taxi de Madrid por vulneración del artículo 15 de la Ley de Competencia Desleal.

Resulta curioso que, aunque los argumentos de la demandante se centraban en la existencia de un conjunto de prácticas desleales, al final se centra en la comisión de una infracción consistente en la «asignación de servicios a los vehículos adscritos a la aplicación que se encuentran circulando y ubicados en contra de lo dispuesto en la legislación del transporte» y con ello infracción de los arts. 182 ROTT y 23 de la Orden FOM/36/2008. Teniendo en cuenta estos hechos, la sentencia no ve responsabilidad de Cabify sobre estos comportamientos al señalarse que nos encontramos simplemente ante una empresa intermediadora de vehículos con conductor y que son directamente los titulares de las licencias de vehículos con conductor los obligados a cumplir con dichas prescripciones y por ende responsables de la infracción de dichas normas administrativas más cuando queda probado que en el contrato de arrendamiento que se firma, la empresa impone a los conductores el respeto de la normativa reguladora de la actividad que se desarrollan (fundamento jurídico cuarto).

\section{CONCLUSIÓN}

No cabe duda de que la economía colaborativa ha evolucionado el sistema de intercambio de bienes y servicios hasta ahora conocido, insertando nuevos prestadores que compiten directamente con operadores ya asentados y regularizados.

En el ámbito del transporte, los casos de Uber o Cabify son el paradigma de la importancia que ha adquirido la economía colaborativa y de la problemática normativa que rodea la misma. En este sentido, la visión clásica de intercambio de prestaciones entre pares a través de la utilización de un intermediario, véase Uber, ha de considerarse, según la jurisprudencia, un servicio de transporte de viajeros por parte de conductores sin la preceptiva licencia, rompiendo con ello el margen de libertad de prestación de servicios alegada por las plataformas.

El cambio de táctica de Uber o Cabify al utilizar el modelo legal de VTC en España ha solventado los inconvenientes jurídicos a la expansión de su actividad. No obstante, el modelo VTC no es ajeno a la problemática competencial con el sector del taxi, empeorado por los vacíos legales producidos en la normativa del arrendamiento de vehículos con conductor y cuyo máximo exponente es la ruptura de la regla 1/30 en el periodo 2009-2013, que ha conllevado la paulatina concesión de licencias vía judicial.

\section{BIBLIOGRAFÍA}

AFI (2017). Impacto socioeconómico de la modernización de los servicios VTC. Recuperado de: http://afi.es/afi/libre/ pdfs/grupo/documentos/completo\%20170510_informe.pdf (diciembre, 2017).

ALGAR, R. (2007). "Collaborative Consumption", Leisure Report, núm. 4, págs. 16-17.

AUTORIDAD CATALANA DE LA COMPETENCIA (2017). Informe IR 31/2017 relativo al Decreto Ley 5/2017, de 1 de agosto, de medidas urgentes para la ordenación de los servicios de transporte de viajeros en vehículos de hasta nueve plazas. Fecha del informe: 4 de septiembre de 2017.

BELK, R. (2013). "You are what you can access: Sharing and collaborative consumption online", Journal of Business Research, núm. 67, págs. 1.596-1.600. DOI: https://doi.org/10.1016/j.jbusres.2013.10.001.

BELK, R. (2014). "Sharing versus pseudo-sharing in Web 2.0", The Anthropologist, vol. 18, núm. 1, págs. 7-23. DOI: https://doi.org/10.1080/09720073.2014.11891518.

BOBOC, S. (2017). “Uber: ¿transportista o intermediaria en el transporte? el caso español”, Revista de estudios europeos, núm. 70, (Ejemplar dedicado a: Economía colaborativa), págs. 7-26.

BOTSMAN, R. \& ROGERS, R. (2010). What's Mine Is Yours: The Rise of Collaborative Consumption. Nueva York: Harper Collins.

CANO CAMPOS, T. (2009). "El transporte público urbano y su regulación jurídica”, CANO CAMPOS, T. y CARBONELL PORRAS, E. (dir. congres.), Derecho público del transporte en la ciudad: renovación y nuevas perspectivas de la movilidad urbana, Universidad Complutense, Facultad de Derecho, págs. 391-447.

CANO CAMPOS, T. (2010). "La regulación del transporte público urbano", en MUÑOZ MACHADO, S. (dir.), Derecho de la regulación económica, vol. 6, 2010 (Transportes), Madrid, lustel, págs. 309-362. 
REALA. Nueva Época - N. 9 9, Abril 2018 - ISSN: 1989-8975 - DOI: 10.24965/reala.v0i9.10470 - [Págs. 128-147]

El arrendamiento de vehículos con conductor (VTC) y su entramado jurídico: el avance de Uber, Cabify y la economía colaborativa Nicolás Alejandro Guillén Navarro

CARBONELL PORRAS, E. (2010). "Directiva de Servicios y transportes terrestres", Revista Aragonesa de Administración Pública, núm. extra 12 (Ejemplar dedicado a: El impacto de la directiva Bolkestein y la reforma de los servicios en el Derecho Administrativo), págs. 469-493.

CARBONELL PORRAS, E. (2017). "Capítulo quincuagésimo octavo. El arrendamiento de vehículos con conductor: servicio de transporte público y nuevas tecnologías", en PAREJO ALFONSO, L. J. y VIDA FERNÁNDEZ, J. (coords.), Los retos del Estado y la Administración en el siglo xxi: libro homenaje al profesor Tomás de la QuadraSalcedo Fernández del Castillo, vol. 2, tomo 2 (Volumen II), págs. 1.717-173.

COMISIÓN EUROPEA (2016). Comunicación de la comisión al Parlamento europeo, al consejo, al Comité económico y social europeo y al Comité de las regiones. Una Agenda Europea para la economía colaborativa. COM (2016) 356 final. Recuperado de: $h$ ttp://eur-lex.europa.eu/legal-content/ES/TXT/?uri=CELEX\%3A52016AE3545 (enero de 2018).

COMISIÓN EUROPEA (2016b). Study on passenger transport by taxi, hire car with driver and ridesharing in the EU, Bruselas, septiembre 2016. Recuperado de: https://ec.europa.eu/transport/sites/transport/files/2016-09-26-paxtransport-taxi-hirecar-w-driver-ridesharing-final-report.pdf.

COMITÉ ECONÓMICO Y SOCIAL EUROPEO (2016). Dictamen del Comité Económico y Social Europeo sobre la «Comunicación de la Comisión al Parlamento Europeo, al Consejo, al Comité Económico y Social Europeo y al Comité de las Regiones - Una Agenda Europea para la economía colaborativa» (COM (2016) 356 final. Recuperado de: $h$ ttp://eur-lex.europa.eu/legal-content/ES/TXT/PDF/?uri=CELEX:52016AE3545\&from=ES (enero de 2018).

COMITÉ EUROPEO DE LAS REGIONES (2017). Dictamen del Comité Europeo de las Regiones - Economía colaborativa y plataformas en línea: una visión compartida de ciudades y regiones (2017/C 185/04). Recuperado de $h$ ttp://eur-lex.europa.eu/legal-content/ES/TXT/PDF/?uri=CELEX:52016IR4163\&from=ES (enero de 2018).

COMISIÓN NACIONAL DE LOS MERCADOS Y LA COMPETENCIA (2016). Informe económico sobre las restricciones a la competencia incluidas en el Real Decreto 1057/2015 y en la Orden FOM/2799/2015, en materia de vehículos de alquiler con conductor - UM/085/15 y acumulados. Recuperado de: https://www.cnmc.es/ file/107176/download.

CONTRERAS DELGADO DE COS, J. M., SILOS RIBAS, M. y SOBRINO RUIZ, M. (2017). "Capítulo duodécimo. La economía colaborativa en los sectores regulados (III). Transporte de viajeros", en ALFONSO SÁNCHEZ, R. y VALERO TORRIJOS, J., Retos jurídicos de la economía colaborativa en el contexto digital, Cizur Menor (Navarra): Thompson Reuters Aranzadi, págs. 309-335.

CRUZ PEÑA, J. (2017). El vacío legal (pese al conflicto) que permite a Uber y Cabify competir contra el taxi. El Confidencial de 3 de junio. Recuperado de: https://www.elconfidencial.com/economia/2017-06-03/uber-cabify-taxilicencias-vtc-transporte_1392749/.

DENNING, S. (2014). Three Strategies for Managing the Economy of Access. Forbes - online edition.

DELONG, J. B. \& SUMMERS, L. H. (2001). "The New Economy: Background, Historical Perspective, Questions, and Speculations", Economic Review-Federal Reserve Bank of Kansas City, 86 (4), págs. 29-54.

DOMÉNECH PASCUAL, G. (2015). "La regulación de la economía colaborativa (El caso «Uber contra el taxi»)", CEFLegal: revista práctica de derecho. Comentarios y casos prácticos, 175-176, págs. 61-104.

DOMÉNECH PASCUAL, G. (2016). "El impacto de la economía colaborativa sobre la regulación del taxi”, en PUETZ, A.; PETIT LAVALL, M. V. (dirs.), La eficiencia del transporte como objetivo de la actuación de los poderes públicos: liberalización y responsabilidad, Madrid, Marcial Pons, págs. 37-59.

DOMÉNECH PASCUAL, G. (2017). "Capítulo 10. La regulación de la economía colaborativa en el sector del taxi y los VTC”, en MONTERO PASCUAL, J. J., La regulación de la economía colaborativa: Airbnb, BlaBlaCar, Uber y otras plataformas, Valencia: Tirant lo Blanch, págs. 351-401.

DURÁN SÁNCHEZ, A.; ÁlVAREZ GARCíA, J.; DEL RíO RAMA, M. C.; MALDONADO-ERAZO, C. P. (2016). "Economía colaborativa: análisis de la producción científica en revistas académicas", Revista de Gestão e Secretariado - GeSec, São Paulo, vol. 7, núm. 3, págs. 1-20. DOI: https://doi.org/10.7769/gesec.v7i3.617.

FELSON, M. y SPAETH, J. L. (1978): "Community Structure and Collaborative Consumption: A routine activity approach", American Behavioral Scientist, vol. 21, núm. 4, marzo-abril, págs. 614-624. DOI: https://doi. org/10.1177/000276427802100411.

FRIEDMAN, G. (2014). "Workers without employers: shadow corporations and the rise of the gig economy", Review of Keynesian Economics (2), págs. 171-188. DOI: https://doi.org/10.4337/roke.2014.02.03.

GACETA DEL TAXI (2017). El TS concede las primeras 80 VTC de las 6.000 pendientes. Recuperado de: $h t t p: / / w w w$. gacetadeltaxi.com/el-ts-concede-las-primeras-80-vtc-de-las-6.000-pendientes-7463 (noviembre de 2017).

GÓRRIZ LÓPEZ, C. (2015). "Uber. Transporte de pasajeros y competencia desleal”, Revista de derecho del transporte: Terrestre, marítimo, aéreo y multimodal, núm. 16, págs. 77-98.

GUIJARRO GONZÁLEZ, E. (2015). "Limitaciones en las autorizaciones para el ejercicio de arrendamiento de vehículos con conductor (VTC's)", Revista española de la función consultiva, 24, págs. 209-235.

JARNE MUÑOZ, P. (2015): "Uber ante el Tribunal de Justicia de la Unión Europea: la incidencia del recurso a las plataformas en línea en la calificación jurídica de los servicios prestados”, Democracia Digital e Governo Eletrônico, vol. 2, núm. 13, págs. 111-122.

JARNE MUÑOZ, P. (2016): “El consumo colaborativo en España: experiencias relevantes y retos de futuro", Revista CESCO de Derecho de Consumo, 17, págs. 62-75. 
LEIÑENA MENDIZÁBAL, E. (2015). "Los nuevos sistemas de utilización compartida de vehículos de transporte (carpooling y car sharing): entre la economía colaborativa y la competencia desleal", Revista de Derecho Mercantil, 296, págs. 283-334.

LESSIG, L. (2008). Remix: Making art and commerce thrive in the hybrid economy. New York: Penguin. DOI: https:// doi.org/10.5040/9781849662505.

LÓPEZ-IBOR, R. A., BIAZZI SOLOMONOFF, R. y CABRILLO, F. (2017). "Taxi Driver 2.0. ¿Por qué UBER ya ha ganado la batalla?", Papeles de economía española, núm. 151, págs. 172-188.

MAESTRE, J. (2001). "Análisis de la directiva de comercio electrónico y del anteproyecto de ley de servicios de la sociedad de la información", Revista de la contratación electrónica, núm. 18, págs. 47-70.

MINISTERIO DE FOMENTO (2017). Transporte de viajeros. Turismos. Distribución de autorizaciones. Disponible en: http://www.fomento.gob.es/transportes/webpturi.pdf (septiembre de 2017).

MOLZ, J. G. (2012): "CouchSurfing and network hospitality: «lt's not just about the furniture»", Hospitality \& Society, vol. 1, núm. 3, págs. 215-225. DOI: https://doi.org/10.1386/hosp.1.3.215_2.

MUÑIZ ESPADA, E. (2002). "Algunas consideraciones sobre la nueva ley de servicios de la sociedad de la información y de comercio electrónico", en CABANILLAS SÁNCHEZ, A. (coord.), Estudios jurídicos en homenaje al profesor Luis Díez-Picazo, vol. 2 (Derecho civil, derecho de obligaciones), Madrid, Civitas, págs. 2.677-2.694.

OLMEDO PERALTA, E. (2017). "Liberalizar el transporte urbano de pasajeros para permitir la competencia más allá de taxis y VTC: Una cuestión de política de la competencia", Revista de estudios europeos, núm. 70 (Ejemplar dedicado a: Economía colaborativa), págs. 250-283.

ORGANIZACIÓN PARA LA COOPERACIÓN Y EL DESARROLLO ECONÓMICO (2007). Taxi Services: Competition and Regulation, OECD Competition Policy Roundtables.

RAUCH, D. E. \& SCHLEICHER, D. (2015). "Like Uber, but for Local Governmental Policy: The Future of Local Regulation of the Sharing Economy", George Mason Law \& Economics Research Paper, (15-01). DOI: https://doi. org/10.2139/ssrn.2549919.

RIVERO GONZÁLEZ, M. D. (2003). "El comercio electrónico con consumidores en la Ley de servicios de la sociedad de la información y de comercio electrónico", Revista de gestión pública y privada, núm. 8, págs. 221-252.

RODRIGUES, R. \& DRUSCHEL, P. (2010). "Peer-to-peer systems". Communications of the ACM, 53 (10), págs. $72-$ 82. DOI: https://doi.org/10.1145/1831407.1831427.

RUSSO, A. P. y QUAGLIERI DOMÍNGUEZ, A. (2014): "La lógica espacial del intercambio de casas: una aproximación a las nuevas geografías de lo cotidiano en el turismo contemporáneo", Scripta Nova: Revista electrónica de geografía y ciencias sociales, 18: 463-499.

RUSSO, A. P. (2015): "La explosión del turismo colaborativo y los retos para el modelo turístico español", en AGUILÓ PÉREZ, E. y ANTÓN CLAVÉ, S.: 20 retos para el turismo en España, Madrid, editorial Pirámide: 113-134.

SOLA TEYSSIERE, J. (2002). "La Ley de Servicios de la sociedad de la información y de comercio electrónico: breve informe de contenidos", Administración de Andalucía: revista andaluza de administración pública, núm. 48, págs. 369-388.

TARRÉS VIVES, M. (2012). "La «Ley ómnibus», el taxi y el arrendamiento de vehículos con conductor", en VICENÇ AGUADO I CUDOLÀ, V. y NOGUERA DE LA MUELA, B. (coords.), El impacto de la Directiva servicios en las administraciones públicas: aspectos generales y sectoriales, Barcelona, Editorial Atelier, págs. 289-306.

TRANSPORT FOR LONDON (2017): Licensing decision on Uber London Limited, Recuperado de: https://tfl.gov. uk/info-for/media/press-releases/2017/september/licensing-decision-on-uber-london-limited?intcmp $=50167$ (septiembre de 2017).

TRIBUNAL DE JUSTICIA DE LA UNIÓN EUROPEA (2017). Conclusiones del Abogado General en el asunto C-434/15 Asociación Profesional Élite Taxi / Uber Systems Spain, S. L. Nota de prensa. Recuperado de: https:// curia.europa.eu/jcms/upload/docs/application/pdf/2017-05/cp170050es.pdf.

VELEIRO REBOREDO, B. (2002). "La Ley 34/2002, de 11 de julio, de Servicios de la Sociedad de la Información y de Comercio Electrónico", Actualidad jurídica Aranzadi, núm. 512, págs. 1-9. 